\title{
Interfacial engineering for silica nanocapsules
}

David Wibowo, Yue Hui, Anton P.J. Middelberg, Chun-Xia Zhao*

Australian Institute for Bioengineering and Nanotechnology, The University of Queensland, St Lucia, QLD 4072, Australia.

*Correspondence:

C.-X Zhao

Telephone: +61-7-3346-4189

Fax: +61-7-3346-4197

E-mail: z.chunxia@uq.edu.au

Submitted to: Advances in Colloid and Interface Science 


\section{Highlights}

- Various approaches for synthesis of silica nanocapsules are presented.

- Special emphasis is on the synthesis methods and interfacial engineering strategies.

- Strategies for cargo-encapsulation in silica nanocapsules are discussed.

- Applications of various forms of core-shell silica nanocapsules are reviewed.

\section{Abstract}

Silica nanocapsules have attracted significant interest due to their core-shell hierarchical structure. The core domain allows the encapsulation of various functional components such as drugs, fluorescent and magnetic nanoparticles for applications in drug delivery, imaging and sensing, and the silica shell with its unique properties including biocompatibility, chemical and physical stability, and surface-chemistry tailorability provides a protection layer for the encapsulated cargo. Therefore, significant effort has been directed to synthesize silica nanocapsules with engineered properties, including size, composition and surface functionality, for various applications. This review provides a comprehensive overview of emerging methods for the manufacture of silica nanocapsules, with a special emphasis on different interfacial engineering strategies. The review starts with an introduction of various manufacturing approaches of silica nanocapsules highlighting surface engineering of the core template nanomaterials (solid nanoparticles, liquid droplets, and gas bubbles) using chemicals or biomolecules which are able to direct nucleation and growth of silica at the boundary of twophase interfaces (solid-liquid, liquid-liquid, and gas-liquid). Next, surface functionalization of silica nanocapsules is presented. Furthermore, strategies and challenges of encapsulating active molecules (pre-loading and post-loading approaches) in these capsular systems are critically discussed. Finally, applications of silica nanocapsules in controlled release, imaging, and theranostics are reviewed. 
Keywords: Silica; Capsules; Interfaces; Core-Shell; Encapsulation; Controlled release

\section{Contents:}

1. Introduction

2. Approaches for making silica nanocapsules

2.1. Templates for interfacial engineering

2.1.1. Solid nanoparticles

2.1.2. Emulsion droplets

2.1.3. Gas bubbles

2.2. Silica-shell formation strategies

2.2.1. Chemical surfactants

2.2.2. Biomolecules

2.3. Surface functionalization of silica nanocapsules

3. Encapsulation approaches

3.1. Post-loading

3.2. Pre-loading

4. Applications of silica nanocapsules

4.1. Controlled release

4.2. Imaging

4.3. Theranostics

5. Conclusions

Acknowledgements

References 


\section{Introduction}

In the past decades, considerable progress has been made in the design, synthesis and application of core/shell nanostructured materials [1-6]. Nanocapsules represent a class of core/shell structure composed of a solid shell that surrounds a core-forming space available to entrap active molecules [7]. The tailorable functionalities of both core and shell endow nanocapsules with new properties, thus rendering it attractive as a superior nanocarrier platform for loading and delivery of functional cargoes. Various types of cargoes have been loaded into the core domain of nanocapsules, including drugs, genes, proteins, imaging agents, pesticides, and catalysts, since the hollow core allows high loading-capacity of active molecules as compared to their solid- and porous- nanoparticle counterparts. The nanocapsules shell, on the other hand, serves to: (i) protect the cargo against premature decomposition (e.g., by photolysis, hydrolysis, microbial, or oxidation/reduction); (ii) protect the environment where the nanocapsules are dispersed against toxicity of the cargo; (iii) provide accessible and stimulisensitive pathways for cargo release; and (iv) enhance dispersibility and stability of the nanocapsules in a given medium. While the core composition determines whether the nanocapsules are intended to be applied in biomedical, agricultural, or chemical fields, the shell material also plays an important roles in nanocapsular performance.

Inorganic silica has received a great deal of attention as a shell material encapsulating a core [8-11] because of its unique features, including: (i) optical transparency; (ii) stable and dispersible in aqueous medium; (iii) diffusional barrier; (iv) biocompatible (as the U.S. Food and Drug Administration (FDA) considered silica, in an amorphous form, as Generally Recognized As Safe (GRAS) material [12]); and (v) tunable physical (e.g., thickness, porosity, and mechanical strength) and chemical (e.g., charge, functionality, and reactivity) properties. To enhance the performance of silica nanocapsules, much effort has been directed toward the interfacial engineering of the silica shell, both at the silica framework (siloxane bonds, $\equiv \mathrm{Si}-\mathrm{O}-$ 
$\mathrm{Si} \equiv$ ) and/or the silica surface (silanol groups, $\equiv \mathrm{Si}-\mathrm{OH}$ ) level. For example, engineering silica nanocapsules with a 'stealthy' polymer such as poly(ethylene glycol) (PEG) can allow the nanocapsules to be dispersed in biological fluids and also enhance their bioavailability hence circulation times in vivo [13]. Further conjugation of silica nanocapsules with stimuliresponsive, targeting, optical, and contrast agents enhances their performance for controlled release, targeted delivery, and imaging/diagnosis. Functionalization of the silica shell is facile through well-established silane chemistry, and thus a plethora of conjugation strategies have been developed. These features of silica combined with the merits of core/shell structure to load active molecules with high-capacity have been driving the development of a cargo loaded, multifunctional and stimuli-sensitive silica nanocapsule (Fig. 1).

\section{Fig. 1.}

Silica nanocapsules in this article refer to hollow core or soft material-filled core that is surrounded with a silica shell. A large number of synthesis approaches are becoming available for the preparation of silica nanocapsules. Template-based methods are often used as they typically result in a well-defined size, shape, and configuration, due to the directing effect of the template. Various molecules have been used to modify the surface of templates, i.e., solid nanoparticles, emulsion droplets, and gas bubbles, as well as to direct silica formation exclusively at the boundary of solid-liquid, liquid-liquid, or gas-liquid interfaces, respectively. In addition, the use of biomolecules has recently emerged as an attractive strategy to develop bioinspired silica nanocapsules as they promote 'green' reaction conditions to form silica. Significant efforts have also been made to tailor the surface chemistry of silica nanocapsules hence evolving nanocapsules as an ideal nanocarrier platform, which has in turn catalyzed fundamental research and new applications of silica nanocapsules.

In this review, the focus is placed on recent research progress in the template-based synthesis of silica nanocapsules and key promising applications. This review article is 
organized as follows. In Section 2, the manufacturing approaches of silica nanocapsules are overviewed highlighting surface engineering of the core template materials (solid nanoparticles, liquid droplets and gas bubbles) dispersed in aqueous solutions. We intend to restrict the synthesis strategies to the basis of interfacial engineering of the core template using (bio)molecules that are able to both stabilize the template and direct nucleation and growth of silica at the boundary of two-phase interfaces (solid-liquid, liquid-liquid, and gas-liquid). Therefore, macromolecules such as micelles, vesicles, or polymeric aggregates that selfassemble to facilitate silica formation in bulk aqueous solution, instead of at interfaces, will not be discussed in this review. The interface chemistry of silica nanocapsules is further explored for making surface-engineered nanostructures with multiple functionalities. In Section 3, strategies and challenges associated with the encapsulation approaches are critically discussed. In Section 4, the applications of silica nanocapsules are overviewed mainly in the following areas: controlled release, imaging, and theranostics. Finally, we conclude with our opinions on the future direction of the field and important areas for further research.

\section{Approaches for making silica nanocapsules}

Fig. 2 shows the general procedure to synthesize a cargo-loaded, surface-functionalized silica nanocapsule using a template. A template, either solid nanoparticle, emulsion droplet, or gas bubble, is firstly prepared and simultaneously stabilized by adsorption of either molecules or biomolecules. By adding a silica precursor, the (bio)molecules can then induce interfacial nucleation and growth of silica surrounding the template to form a template-core silica-shell nanocapsule. Removal of the template can be achieved by calcination at high temperature or by physical dissolution using acids, bases or organic solvents, depending on the chemical and structural differences of the template as well as on the ultimate applications of the nanocapsule. Subsequently, the resultant silica nanocapsule can be loaded with active molecules. Addition of a functional molecule that has chemical affinity with the silica shell can then fabricate 
surface-functionalized silica nanocapsule containing a functional cargo (Fig. 2). In this section, a comprehensive overview of the interfacial engineering on a pre-synthesized template used for making silica nanocapsules will be presented (Section 2.1). Next, types of macromolecules decorated on the template surface to enhance the stability of the template as well as the chemical affinity to silica will be explained (Section 2.2). Further, surface modification techniques will be explored demonstrating the surface-chemistry tailorability of silica for developing silica nanocapsules with multiple functionalities (Section 2.3).

\section{Fig. 2}

\subsection{Templates for interfacial engineering}

Templating approach using hard (i.e., solid nanoparticle) or soft (i.e., emulsion droplets or gas bubbles) template is commonly used to form cargo-loaded, multifunctional silica nanocapsules. The three different strategies based on solid nanoparticles, emulsion droplets and gas bubbles for the synthesis of silica nanocapsules are compared and presented in Table 1. Each of the strategies will be discussed in detail in the following sections.

\section{Table 1}

\subsubsection{Solid nanoparticles}

Silica nanocapsules can be formed by templating pre-formed solid nanoparticles as hard templates (Table 2). Surface chemistry of the template plays significant roles during the synthesis of a silica shell. The compatibility between the template surface and a silica precursor in an aqueous solution is determined by their chemical or electrostatic affinity. Therefore, some hard templates require surface modification with an appropriate functional group prior to silica growth in order to enhance the coupling (thus deposition) of silicate species to the template surfaces. Tuning the reaction conditions such as rate of reaction and type of additives are also important as thermodynamically- and kinetically- controlled synthesis can result in different physical (e.g., shell thickness, pore structure, and pore size) and chemical (e.g., silicate 
condensation degree) properties of the resultant silica. Finally, the hard template needs to be removed from the core domain to form hollow silica nanocapsules in order to enable loading of active molecules.

\section{Table 2}

The assembly and engineering of silica at solid-liquid interfaces can be classified into two general categories: (i) sol-gel reactions of silica precursors on the surfaces of either pristine or surface-modified hard templates; and (ii) controlled deposition of pre-formed silica nanoparticles on hard templates. In the first category, the most straightforward technique for silica sol-gel templating against a hard template is the use of silica nanoparticles as the hard template. The silanol group ( $\equiv \mathrm{Si}-\mathrm{OH})$ on the silica surface can facilitate interfacial sol-gel reaction with a silica precursor to form a silica shell [14-22]. Other hard templates including hematite $\left(\alpha-\mathrm{Fe}_{2} \mathrm{O}_{3}\right)$ [23] and carbon nanoparticles [24-26] can also direct nucleation and growth of silica without an additional surface-modification step prior to silica growth, as their surfaces are rich in hydroxyl group. However, hard templates like polymeric nanoparticles (e.g., poly(vinylbenzylchloride) [27], poly(tert-butylacrylate) [28], and poly(styrene) latex [29-33]), calcium carbonate [34-38] and hydroxyapatite [39] require surface modification prior to the interfacial sol-gel reaction. Methods for surface modification of templates include introducing functional groups on the surface simultaneously when the template is synthesized. Surface functionalities can be used to tune the compatibility between the surface and the precursors. For example, poly(styrene) latex nanoparticles (PS) on which the surfaces were modified with amine groups $\left(-\mathrm{NH}_{3}{ }^{+}\right)$[29, 40] or zwitterionic groups $\left(-\mathrm{NH}_{3}{ }^{+} /-\mathrm{COO}^{-}\right)$[29] attracted the negatively-charged silicate species from silica precursor through electrostatic interactions under basic conditions which then led to homogeneous silica coating. However, under similar $\mathrm{pH}$ conditions, sulfonate group $\left(-\mathrm{SO}_{3} \mathrm{H}\right)$ functionalized PS template resulted in non-uniform silica coating and self-nucleation of silica in bulk solution [40]. This was most likely due to a 
lack of interaction between silica nuclei and template particles as both the template and the silica nuclei were negatively charged in basic solutions. This result demonstrated the importance of electrostatic density matching between the template surface and the silica precursor to enable silica formation.

To form hollow silica nanocapsules enabling cargo loading, the hard template needs to be removed (Fig. 3). The process of removing the hard template is critical and must be defined to retain the integrity of the silica shell as well as to generate hollow spheres having a high degree of uniformity and dispersibility. Hard-template cores can be removed based on a structural difference between the template and the silica shell, especially when the silica nanoparticle is used as a hard template (Figs. 3A and 3B). For example, Shi et al. prepared core-shell silica nanoparticles composed of a silica core and silica shell $[14,15]$. The silica core was synthesized by the Stöber method using tetraethoxysilane (TEOS) as the single silicaprecursor, while the silica shell was formed by co-assembly between TEOS and octadecyltrimethoxysilane ( $\mathrm{C}_{18} \mathrm{TMS}$ ). This resulted in the silica core having a lower silicate condensation degree than the shell, meaning that the silica core had higher density of Si-OH bonds which are more easily disintegrated than $\mathrm{Si}-\mathrm{O}-\mathrm{Si}$ bonds. Moreover, the long hydrophobic chain of $\mathrm{C}_{18}$ TMS formed hydrophobic domains within the shell which created a more open structure for acidic or basic etching-agents (e.g., $\mathrm{Na}_{2} \mathrm{CO}_{3}[14,16], \mathrm{NH}_{4} \mathrm{OH}$ [14], or $\left.\mathrm{HF}\left(60^{\circ} \mathrm{C}\right)[15]\right)$ to penetrate through the shell and selectively remove the solid silica core, while keeping the silica shell mostly intact (Fig. 4). Hollow silica nanocapsules can be formed based on an Ostwald-ripening mechanism by mixing silica nanoparticles with a strong base $\mathrm{NaBH}_{4}$ [41]. In this process, silica nanoparticles were gradually dissolved in the $\mathrm{NaBH}_{4}$ solution until silicates supersaturated around the nanoparticles. Then the slowly formed metaborate, $\mathrm{BO}_{2}{ }^{-}$, from the decomposition of $\mathrm{NaBH}_{4}$ induced regrowth of silica shells at the expense of particle cores and eventually led to hollow-core silica-shell nanocapsules. The 
surface structure of resultant silica shells can be adjusted to either smooth or rough by carrying out the reactions under ambient [41] or hydrothermal [42-44] conditions, respectively. Another way to remove the core is based on compositional difference, for example, between the PS template and the silica shell (Fig. 3C). This can be achieved by calcination at high temperature or by chemical treatment using strong acidic/basic solutions or organic solvents.

Fig. 3

Fig. 4

In the second category, construction of hollow silica nanocapsules is by controlled deposition of pre-formed silica nanoparticles onto a hard template. This method was developed by Möhwald and Caruso et al. [45]. The idea was to use a layer-by-layer (LbL) colloidal templating strategy in which electrostatic forces facilitate layer build-up [45-48]. Templating PS nanoparticles are frequently used in LbL methods. In a typical synthesis, negatively-charged PS nanoparticles are alternately deposited with positively-charged polymers and negativelycharged silica nanoparticles. Subsequent removal of the cores using tetrahydrofuran yielded hollow silica nanocapsules [45-47]. The LbL assembly method allows controllable thicknesses on the nanometer scale by the deposition cycles of bilayer silica nanoparticles/cationic polymers as well as by the assembly conditions (e.g., salt concentration). It was demonstrated that the deposition cycles (1-5) determined silica shell thickness (25-210 nm), which in turn affect the mechanical strength of the shell [45], and control of salt concentration allowed silica nanoparticles to pack closely at the template surfaces [48].

Despite the widely used hard template method to form silica nanocapsules, its disadvantage lies in the harsh conditions employed for core-removal which are not environmentally friendly, such as using high temperature or highly acidic/basic/organic solutions (Table 2). In addition, incomplete removal of the template can result in entrapping the template residues inside the core of nanocapsules. Overall, this procedure has limitations 
that may impact scale-up production for practical applications. For example, the repeated cycles of coating and washing applied during the LbL assembly may lower the synthesis efficiency and resulted in an increased hollow nanoparticle size. Therefore, the development of alternative approaches is of significant research and industrial interest.

\subsubsection{Emulsion droplets}

In addition to the hard-templating approach, the soft-templating method using emulsions offers an alternative synthetic route for making silica nanocapsules. Emulsions can be formed by mixing two immiscible liquid phases (i.e., oil and water) together with an energy input, such as by shaking, stirring, homogenizing, or ultrasonic irradiation, which results in one phase (dispersed phase) dispersed in another (continuous phase) in the form of droplets. In general, emulsions are thermodynamically unstable as the droplets constantly move as a result of Brownian motion, applied shear or thermal energy, or gravitational forces which eventually cause droplet coalescence and Ostwald ripening. Therefore, surfactants are required to increase their kinetic stability. Typically, there are two types of emulsions used for making silica nanocapules, that are, oil-in-water (O/W) [49-64] and water-in-oil (W/O) [65-71] emulsions (Table 3). The formation of these types of emulsions is generally controlled by the volume fraction of the oil and water phases, the type and amount of surfactant(s) added to stabilize the emulsions as well as the conditions during emulsification such as temperature. In order to make silica nanocapsules, the emulsions are mixed with silica precursors, which then results in silica precipitation exclusively at the interfacial region between dispersed and continuous phases forming shells surrounding the emulsion droplets. The presence of surfactants surrounding the droplets is of great importance as they function not only to maintain the droplet stability, but also to induce the silica formation preferentially at the interfaces. The types of surfactants are detailed in Sections 2.2 (chemicals) and 2.3 (biomolecules).

\section{Table 3}


O/W emulsions having different oil and surfactant compositions have been investigated for making silica nanocapsules (Fig. 5). Soft-templating O/W emulsion can also be used to fabricate hollow silica nanocapsules thereby using a silica precursor TEOS to form an O/W emulsion in aqueous solution/sol [50-52]. Control of the reaction conditions (e.g., solvent type and ratio, surfactant concentration, stirring rate, and interfacial reaction time) is important so that the formation of TEOS droplets and the interfacial reaction could occur sequentially. For example, some organic additives (co-solvent) such as $N, N$-dimethylformamide (DMF) have been used as bridging co-solvent that cooperates synergistically with TEOS by promoting the formation and dispersion of TEOS droplets in the aqueous solution and by accelerating the hydrolysis of TEOS at the interface (Fig. 5A) [50]. Once the TEOS droplets were consumed, hollow mesoporous silica spheres can be produced, and the pore structure, shell thickness and sphere dimension were controllable by varying the amount of DMF. In addition, the volume ratio of ethanol-to-water and the concentration of surfactant have also been demonstrated to play key roles in stabilizing TEOS droplets enabling the formation of hollow silica nanoparticles instead of solid silica nanoparticles (Fig. 5B). Recently, biomolecules have attracted attention to facilitate silica nanocapsules formation by templating $\mathrm{O} / \mathrm{W}$ nanoemulsions [60-64]. We developed an emulsion and biomimetic dual templating approach for making oil-core silica-shell nanocapsules by using either rationally designed peptides (Fig. 5C) [60] or proteins (Fig. 5D) [63] to both stabilize emulsion droplets as well as catalyze silica formation preferentially at oil-water interfaces. The silica shell thickness was tunable by controlling reaction $\mathrm{pH}$, reaction time, and silica precursor concentration [60, 61, 64].

Fig. 5

Templating W/O emulsions for the synthesis of silica nanocapsules have also been demonstrated (Fig. 6). Mou et al. utilized Triton ${ }^{\circledR} \mathrm{X}-100$ and hexanol as surfactant and cosurfactant, respectively, to prepare stable W/O emulsions which can then be used as the 
template for synthesizing silica nanocapsules (Fig. 6A) [65]. Using the same W/O emulsion system, Jatupaiboon et al. were able to tune the emulsion-core diameter (i.e., 7-16 nm) and the silica-shell thickness (i.e., 5-13.5 nm) by controlling the concentration of silica precursor (Fig. 6B) [66]. Moreover, control of the amount of surfactant and silica precursor can tune the pore size distribution, specific surface area and shell thickness of silica nanocapsules (Fig. 6C) [67]. Silica nanocapsules encapsulating W/O emulsions have been beneficial in encapsulating enzymes to carry out intracellular biocatalysis taking advantage of the hydrophilicity and high loading capacity of the core (Fig. 6D) [68].

Fig. 6

Compared to hard-templating methods, one of the most attractive advantages of the softtemplating method is facile and efficient encapsulation of functional cargoes (e.g., agrochemicals, therapeutics, metal nanoparticles, etc.). A big variety of cargoes can be easily encapsulated in $\mathrm{O} / \mathrm{W}$ or $\mathrm{W} / \mathrm{O}$ emulsions, demonstrating the versatility of emulsion-templated silica nanocapsules (Table 3). Hydrophobic compounds such as pesticide [60, 61], drug [72], and imaging agents [56, 72] can be encapsulated in $\mathrm{O} / \mathrm{W}$ emulsion-templated silica nanocapsules. In addition, $\mathrm{O} / \mathrm{W}$ emulsion-templated silica nanocapsules have been used as adsorbents to sequester lipophilic compounds [53, 54]. On the other hand, hydrophilic compound such as enzymes $[68,69]$ can be encapsulated in silica nanocapsules using W/O emulsions as templates. Facile encapsulation can be achieved by directly dissolving the cargo in the dispersed phase prior to the emulsification and the silica-shell formation, avoiding the template-removal and core-refilling processes prevalent in hard-templating methods. Moreover, the liquid droplet cores can be easily removed, if necessary, by gentle evaporation or dissolution using mild solvents (e.g., ethanol) after shell formation.

\subsubsection{Gas bubbles}


Another soft-templating method is using gas bubbles as templates. Sol-gel reactions occur at the gas-liquid interface where gas bubbles are encapsulated by the forming silica shells. As the gas bubbles constitute the hollow cores of the nanocapsules, gas-templated hollow silica nanocapsules are more facile as they do not require template removal. Previous investigations have demonstrated that gas bubbles could be generated in an aqueous solution by two methods: (i) flowing of gas or gas mixtures [73, 74]; and (ii) ultrasonic irradiation [75-77]. An example of the first method involved the use of a highly reactive $\mathrm{SiF}_{4}$ gas as silica precursor. To initiate the formation of solid silica at the gas-liquid interfaces, $\mathrm{SiF}_{4}$ gas was flowed into a container of water through an orifice, and then hydrolysis occurred on the surface of the formed gas bubbles [74]. The presence of silica nuclei on the surface of gas bubbles stabilized the gasliquid interface and impeded bubble coalescence. The diameter of the produced silica materials was $813 \mathrm{~nm}$ with a size distribution of 360-1400 nm and a shell thickness of $12 \mathrm{~nm}$. Other inert gas like $\mathrm{N}_{2}$ has also been used to generate gas bubble templates [73]. To form hollow silica nanocapsules, a precursor solution (pre-hydrolyzed TEOS) containing a surfactant (as a blowing agent) was blown into a heating tube by a nitrogen gas flow. Large parent bubbles were formed and then ruptured into smaller bubbles in which the sizes were dependent on the gas flow rates. By flowing additional ammonia gas (as a catalyst) into the heating tube $\left(200^{\circ} \mathrm{C}\right)$, the sol-gel reactions then occurred at the nitrogen gas-liquid interfaces forming hollow-core silica-shell nanocapsules within seconds [73].

The second method of generating gas bubbles is by an ultrasonic irradiation of an aqueous solution containing a silica precursor and a chemical surfactant (Fig. 7) [75-77]. The ultrasonic irradiation induces the growth and collapse of the cavitation bubbles which focuses and transfers energy from the macroscale (acoustic wave) to the microscale (vapour inside bubbles) producing highly localized pressures and temperatures near air-liquid interfaces. The surfactant diffuses to the interfaces during sonication and stabilizes the cavitating bubbles. 
Simultaneously, the surfactant also induces a cooperative supramolecular-templated deposition of the surfactant and silica surrounding the bubbles, where the local hot spots near the interfaces produced during sonication accelerate the silica growth [75], thus leading to the formation of a solid silica shell with a specific mesostructure. The properties of the resulting silica nanocapsules are influenced by sonication conditions. For example, varying the sonication processing time has been demonstrated to enable control of silica shell thickness, as more bubbles were formed with longer ultrasound irradiation times, thus reducing silica/surfactant available to encapsulate each bubble [77].

Fig. 7

Despite the various quick pathways of making hollow silica nanocapsules with tunable properties by templating gas bubbles, the resulting nanocapsules have either wide size distributions [73-77] (e.g., 100-500 nm, Fig. 2A) and/or non-uniform shell thickness [73] because of limited control over both the bubble formation and silica shell synthesis processes.

\subsection{Shell formation based on sol-gel methods}

Alkoxysilanes, such as tetramethoxysilane (TMOS) and tetraethoxysilane (TEOS), are common silicon-containing precursors used to study silica formation and generate silica-based materials for technological applications. They are water-insoluble, and their reactivity can be efficiently controlled depending on the length and bulkiness of the alkyl chain. In order for solid silica to be produced from alkoxysilanes, hydrolysis and condensation of the precursor must occur prior to concomitant nucleation and growth of solid silica. In general, the hydrolysis and condensation reactions occur based on bimolecular nucleophilic substitution $\left(\mathrm{S}_{\mathrm{N}} 2\right.$-type reaction). At the functional group level, three reactions are generally used to describe the solgel processes as shown below:

$$
\begin{aligned}
& \text { Hydrolysis: } \quad \mathrm{Si}(\mathrm{OR})_{4}+x \mathrm{H}_{2} \mathrm{O} \rightleftarrows(\mathrm{RO})_{4-x}-\mathrm{Si}-(\mathrm{OH})_{x}+x \mathrm{ROH} \\
& \text { Condensation: } \quad \equiv \mathrm{Si}-\mathrm{OR}+\mathrm{HO}-\mathrm{Si} \equiv \rightleftarrows \equiv \mathrm{Si}-\mathrm{O}-\mathrm{Si} \equiv+\mathrm{ROH}
\end{aligned}
$$




$$
\equiv \mathrm{Si}-\mathrm{OH}+\mathrm{HO}-\mathrm{Si} \equiv \rightleftarrows \equiv \mathrm{Si}-\mathrm{O}-\mathrm{Si} \equiv+\mathrm{H}_{2} \mathrm{O}
$$

where $\mathrm{R}$ is an alkyl group $\left(\mathrm{C}_{x} \mathrm{H}_{2 x+1}\right)$.

The hydrolysis reaction replaces the alkoxy group with a hydroxyl group producing a monomer containing silanol groups $(\equiv \mathrm{Si}-\mathrm{OH})$. Complete hydrolysis produces silicic acid, $\mathrm{Si}(\mathrm{OH})_{4}$. However, under most conditions, condensation commences before hydrolysis completes. The condensation reactions involving monomer with silanol groups produces dimer having siloxane bond $(\equiv \mathrm{Si}-\mathrm{O}-\mathrm{Si} \equiv)$ and the by-products alcohol $(\mathrm{ROH})$ and water. The hydrolysis and condensation reactions can be catalyzed by conducting the reactions in acidic or basic conditions. Other factors that affect the silica formation kinetics of solid silica include $\mathrm{pH}$, presence of salts, temperature, identity of precursors (e.g., alkyl chain length and degree of branching) and types of solvent (e.g., polarity) [78].

In addition to alkoxysilane, organosilica precursors silsesquixonanes $\mathrm{X}_{3} \mathrm{Si}-\mathrm{R}-\mathrm{SiX} \mathrm{X}_{3}(\mathrm{R}=$ phenyl (aromatic), ethyl (aliphatic), or vinyl (alkene) group; and $\mathrm{X}=\mathrm{Cl}, \mathrm{Br}, \mathrm{OR}$ ) can also be used as silica precursors. Incorporation of organic groups into the silica framework can produce molecularly organic-inorganic hybrid organosilica with silsesquioxane framework within the silica walls. The presence of organic moieties within silica framework influences their physical (e.g., shell stiffness) and chemical (e.g., hydrophobicity or hydrophilicity) properties. For example, organic moieties like thioether groups with relatively long molecular chain incorporated within silica framework enhanced the global shell-elasticity [79]. Further detail about the synthesis and applications of the hollow organosilica nanoparticles has been reviewed elsewhere [80-82].

A number of methods are often used to generate silica based on hydrolysis of a silica precursor and condensation of the hydrolyzed products (sol-gel reactions): (i) Stöber method, which uses hydroxides (as catalyst), TEOS (as silica precursor) and ethanol (as homogenizing agent) [83]; and (ii) water-glass method, which uses water-soluble sodium silicate as silica 
precursor [29]. The interaction between the template and silicate species during the sol-gel reaction at solid-liquid, liquid-liquid or gas-liquid interfaces can be enhanced by modifying surface chemistry of the template (either during or after the template synthesis) with functional groups which are receptive to silica species. Additionally, tuning the reaction conditions (e.g., reaction time and temperature) and compositions (e.g., precursor concentration) control the properties of silica nanocapsules (e.g., shell thickness, silica-coating homogeneity, and surface texture). Either cationic or hydrogen-bonding molecules, such as chemical surfactants and biomolecules, can induce silica formation through electrostatic interactions with $\equiv \mathrm{SiO}^{-}$(the isoelectric point of silanol ( $\equiv \mathrm{Si}-\mathrm{OH})$-bearing silica species is 2) or hydrogen bond formation with $\equiv \mathrm{Si}-\mathrm{OH}$, respectively. The presence of cationic or hydrogen-bonding molecules at the template surface plays important roles in the formation of silica nanocapsules especially when emulsion templates are used: (i) to stabilize the template; and (ii) to control the hydrolysis and condensation of a silica precursor exclusively at the interface avoiding formation of silica nanoparticles in bulk solution.

\subsubsection{Chemical surfactants}

Chemical surfactants have been widely used to stabilize emulsion templates as they have both hydrophilic 'head' and hydrophobic 'tail' groups in their chemical structure. The surfactants have partial solubility either in water (water-soluble surfactant) or oil (oil-soluble surfactant). This amphiphilic property allows their adsorption onto either O/W (water-soluble surfactants) or W/O (oil-soluble surfactants) interfaces to reduce the interfacial tension of the systems and to provide a protective envelope around the dispersed droplets stabilizing the emulsion by imparting steric barrier or electrostatic charges on the droplet surfaces thus reducing the physical contact between the droplets and decreasing the potential for coalescence. For the synthesis of silica nanocapsules, the surfactants should also be able to induce nucleation and growth of silica preferably at the template surfaces to form a silica shell encapsulating the 
template. In some cases, excess surfactants that are not adsorbed to the emulsion surface have to be removed to avoid silica formation in bulk solution [53, 54]. In addition to their stabilization properties, surfactant molecules can form supramolecular aggregates which function as structure-directing agents for the construction of mesostructures upon surfactant removal in preparing mesoporous silica materials (reviewed in Ref. [82, 84]).

There are commonly used non-ionic and cationic surfactants that have been utilized to both stabilize $\mathrm{O} / \mathrm{W}$ or $\mathrm{W} / \mathrm{O}$ emulsion templates and form silica nanocapsules as mentioned in Table 3. The non-ionic surfactants include $\operatorname{Triton}^{\mathrm{TM}} \mathrm{X}-100$ (poly(ethylene glycol) tertoctylphenyl ether) [55], Pluronic ${ }^{\circledR}$ F-68 (poly(oxyethylene)-b-poly(oxypropylene)) [56], Kolliphor ${ }^{\mathrm{TM}}$ ELP (macrogolglycerol ricinoleate) [57], Brij ${ }^{\circledR} 97$ (poly(oxyethylene) oleyl ether) [53], Tween ${ }^{\circledR} 80$ (poly(ethylene glycol) sorbitan monooleate) [54], Span ${ }^{\circledR} 80$ (sorbitan monooleate) [67], and IGEPAL ${ }^{\circledR}$ CA-520 (poly(ethylene-co-butylene)-b-poly(ethylene oxide)) $[68,69]$. The cationic surfactants are mostly based on quaternary ammonium compounds including cetyltrimethylammonium bromide [49, 51, 52] and cetyltrimethylammonium chloride [50]. Silica formation at liquid-liquid interfaces stabilized by non-ionic surfactants is basically initiated by interactions between the surfactants and the uncharged silica species ( $\equiv \mathrm{Si}-\mathrm{OH})$ through hydrogen bonds. When cationic surfactants are used to stabilize liquidliquid interfaces, the interfacial reactions of silica are induced by interactions of the positivelycharged surfactant and negatively-charged silica species $\left(\equiv \mathrm{Si}-\mathrm{O}^{-}\right)$in basic conditions.

\subsubsection{Biomolecules}

Inspired by Nature, many biomolecules (peptides/proteins) have been investigated for the formation of silica-based nanomaterials owing to their ability to selectively bind, interact with, and direct the nucleation and growth of silica at environmentally friendly conditions. The use of peptides/proteins is advantageous as they can be easily modified by insertion or addition of different amino acid residues through genetic engineering or functionalization with various 
chemical side chains to enhance their capabilities to stabilize interfaces and simultaneously form silica shell. Biomineralizing molecules include proteins extracted from organisms (e.g., silicatein $\alpha$ [85, 86] and silaffins [87]), peptides derived from the naturally-occurring proteins (e.g., R5 peptide [87, 88]), peptides obtained from combinatorial biology [89], and rationally designed peptides/proteins $[60,63,90]$. The specificity of the biomolecules for silicate species may originate from both chemical (nucleophilicity, hydrogen bonding, and charge effects) and structural (morphology) recognition mechanisms. Polar amino acid residues that can facilitate hydrolysis of a silica precursor, to produce silanol and negatively-charged silanolate, include cysteine (C), serine (S), tyrosine (Y), histidine (H) and glutamine (Q). These amino acids promote nucleophilic attack on the silicon atom of TEOS [85, 86], and the nucleophilicity of the serine hydroxyl can be enhanced by the formation of hydrogen bond with adjacent histidine imidazole [91]. Moreover, positively-charged arginine (R) and lysine (K) can electrostatically interact with the silanolate at near-neutral $\mathrm{pH}$, while the hydroxyls of serine (S) and tyrosine (Y) promote hydrogen bonding with silanol [87], which in turn act as nucleation sites and direct silica growth through condensation of the silica species in bulk solution. Depending on the conformation and stereochemical configuration of their constituent amino acids, biomineralizing molecules can self-assemble in bulk solutions serving as scaffolds where the condensation of silica species form layers following the contours of the underlying biomolecule structure, thus governing the morphology of the resulted silica-based materials. Based on these findings, several research groups designed peptides and proteins for the assembly and engineering of silica either in bulk solutions (reviewed in Ref. [92-94]) or at biphasic interfaces i.e., solid-liquid interface [95, 96] and oil-liquid interface [60-64].

Rationally designed SurSi peptide

(Ac-MKQLAHSVSRLEHA

$\mathrm{RKKRKKRKKRKKGGGY-CONH}_{2}$ [60]) and D4S2 protein (M(DPS MKQLADSLHQLARQVSRLEHA) ${ }_{4}$ EPS RKKRKKRKKRKKGGGY) [63]) have been utilized 
to enable stabilization of nanoemulsions while catalyzing formation of silica at oil-water interfaces forming oil-core silica-shell nanocapsules. The bifunctional biomolecules were designed by modularizing a surface-active module with a module for biosilicification activity (Fig. 8A). The surface-active module near the $N$-terminus was designed based on the AM1 peptide surfactant (Ac-MKQLADSLHQLARQVSRLEHA-CONH${ }_{2}$ ) [97] by incorporating hydrophobic (mainly methionine (M), leucine (L), and valine (V) residues) and hydrophilic amino acid residues to impart facial amphiphatic character, thus promoting adsorption at the nanoemulsion interface during nanoemulsion formation (emulsification) hence stabilizing the nanoemulsions. The biosilicification-active module near the $C$-terminus was designed to be rich in cationic amino acid side chains (RKKRKKRKKRKKGGGY) and, upon addition of a silica precursor (TEOS), it catalyzed silica growth at the oil-water interfaces and thus formed a silica shell encapsulating the nanoemulsion core. These biomineralizing peptide and protein enable the formation of silica nanocapsules at near-neutral $\mathrm{pH}$ and ambient temperature without using any toxic organic solvents. Biomineralization of silica at oil-liquid interfaces to synthesize oil-core silica-shell nanocapsules has also been investigated using a layer-by-layer assembly method requiring alternate deposition of oppositely charged biomolecules on a nanoemulsion template (Fig. 8B) [64]. Lecithin was used first to stabilize nanoemulsions through its negative charge-charge repulsions which then allowed adsorption of positivelycharged poly(lysine). Subsequently, negatively-charged silica precursor can be attracted onto the nanoemulsions' surfaces and to eventually form a silica shell.

Fig. 8

\subsection{Surface functionalization of silica nanocapsules}

Surface chemistry of silica nanocapsules dictates how they interact with each other and with the environment where they are dispersed. It plays important roles in the dispersibility, biocompatibility, functionality, and/or targeting specificity of the silica nanocapsules in order 
to make them effective and universally applicable as nanocarrier platforms. When synthesizing silica-based materials using an alkoxysilane as the silica precursor, the resultant silica comprises $\equiv \mathrm{Si}-\mathrm{OH}$ groups at the outer surface which can be modified with organic functional groups. Integrating organic functional groups onto the surface of silica nanocapsules allows for control of the physical (e.g., pore size) and chemical (e.g., charge, functionality, and reactivity) properties of the nanocapsules, which in turn provides high level of versatility and mechanized features to the nanocapsules. Functionalization of silica nanocapsules is independent of the physical structure of the materials, but relies on the surface chemistry of silica nanocapsules, that is, the availability of silanol groups $(\equiv \mathrm{Si}-\mathrm{OH})$ at the interface, particularly free $(\equiv \mathrm{Si}-\mathrm{OH})$ and geminal $\left(=\mathrm{Si}-(\mathrm{OH})_{2}\right)$ silanols. The silanol groups enable conjugation of organic functional groups either through covalent siloxane bonds or electrostatic interactions.

There are two approaches that are commonly used for incorporating functional organic moieties onto silica shells through formation of covalent bonds, i.e., co-condensation and postsynthetic grafting. Using co-condensation methods, an organoalkoxysilane compound is added together with a silica precursor such as TEOS during the synthesis of silica nanocapsules (onepot) [98-102]. In contrast, a post-synthetic grafting process facilitates conjugation of organic functional groups to the exposed silica surfaces after the silica nanocapsules are formed [32, 103-107]. A successful grafting process relies on reactivity, steric factor hence diffusion limitation of the organoalkoxysilane, availability and accessibility of the surface silanol groups. It is therefore important to maintain a large number of surface silanol groups. High-temperature $\left(400-550^{\circ} \mathrm{C}\right)$ applied during template-removal (i.e., calcination) causes reduction in the number of silanol groups as the heating promotes condensation of silanol groups at the interface.

To date, various organic functional groups have been covalently conjugated to silica surfaces of nanocapsules. Methyl functional groups can be grafted onto silica nanocapsules to 
passivate surface silanol groups, thereby increasing surface hydrophobicity thus improving their framework stability toward hydrolysis [102]. Another passive functional group, poly(ethylene oxide), can be used to tune the surface charge of silica nanocapsules which, in turn, reduced the damaging interactions of the nanocapsules with red blood cells and platelets [107]. Reactive organic functional groups can also be incorporated onto silica shells to provide facile linker chemistry (e.g., thiol [98-100], azide [101], alkyl [102, 105], epoxide [32], amine [103, 104, 106], or alkoxy [107]). The linker is especially important for conjugating various functional molecules or biomolecules onto the surfaces of silica nanocapsules, including stimuli-responsive materials (e.g., chitosan [32] and $\alpha$-cyclodextrine [20, 108]), targeting molecules (e.g., antibody [16] and folic acid [20]), fluorescence imaging agents (e.g., near-IR dye [16], coumarin blue dye [57], fluorescein isothiocyanate [31, 58, 64], and rhodamine B isothiocyanate [58]), magnetic resonance imaging (MRI) contrast agent (e.g., MnO [19] and gadolinium complex $[64,70])$, positron emission tomography (PET) imaging contrast agents (e.g., ${ }^{64} \mathrm{Cu}$ chelator [16]) and 'stealthy' polymer (e.g., poly(ethylene glycol) (PEG) [16, 64]).

In addition to covalent bonds, silica shell can also be modified by non-covalent, electrostatic interactions taking advantage of the intrinsic negatively-charged $\equiv \mathrm{Si}-\mathrm{O}^{-}$groups on the silica nanocapsule surface as a result of the deprotonation of silanol groups at nearneutral pH. Layer-by-layer assembly is a widely used method to electrostatically modify the surface chemistry of silica nanocapsules. For example, positively-charged poly(allylamine hydrochloride) and negatively-charged poly(styrene sulfonate) functional groups can be alternately deposited onto silica nanocapsules forming polyelectrolyte multilayers at the interface [109]. These polyelectrolyte multilayers could enhance the mechanical strength and promote stimuli-responsive release of the encapsulated cargo at different $\mathrm{pH}$ and $\mathrm{NaCl}$ concentrations.

\section{Encapsulation approaches}


Silica nanocapsules have provided a versatile platform to encapsulate different types of cargo molecules, ranging from small molecular drugs to macromolecules, inside their interior to exhibit functionality relevant to their ultimate applications. So far, various approaches have been proposed for incorporating different types of substances within silica nanocapsules. The properties of the cargo, such as solubility, radius of gyration or size, and chemical composition, often determine how the cargo can be loaded into silica nanocapsules. Generally, there are two encapsulation approaches, i.e., post-loading and pre-loading, which are discussed in detail in the following sections.

\subsection{Post-loading approach}

Post-loading approaches are widely used to load active molecules into hollow-core silica-shell nanocapsules. A straightforward approach to load the nanocapsules is to exploit diffusion of active molecules from the surrounding medium into the nanocapsule cavity through the shell (Fig. 9). This approach enables loading of a range of materials, such as therapeutic drugs (e.g., bortezomib [31], cefradine [34], doxorubicin [26, 28, 66], ibuprofen [109], and tumor necrosis factor $\alpha$ [32]), genes (e.g., siRNA [17]), nanoparticles (e.g., $\mathrm{Fe}_{3} \mathrm{O}_{4}$ [17]), and agrochemicals (e.g., avermectin [35] and validamycin [36]). The properties of both silica nanocapsules (e.g., the pore size and structure in the shell, the size of hollow cavity, surface heterogeneity and surface chemical properties) and active molecules (e.g., solubility, polarity, structure, molecular weight/size, and hydrophilicity/hydrophobicity) influence the diffusion process and adsorption equilibrium [110]. The incorporation of active molecules in the pre-formed silica nanocapsules is a dynamic and competitive process involving three steps: (i) mass transfer of active molecules from the medium to the nanocapsule surface; (ii) diffusion of the active molecules through the porous shell, which is often considered as the rate-determining step and mostly driven by concentration gradient of the active molecules from the medium to the hollow cavity; and (iii) adsorption and accumulation of the active molecules in the nanocapsule cavity 
or wall. In some cases, active molecules can only be deposited within the porous silica shell [34] or adsorbed onto the external layer of the nanocapsule's surface when the size of the active molecules is larger (e.g., opti-E2 protein with a length of $12-13 \mathrm{~nm}$ and a width of 3-4 nm [18]) than the pore size of the silica shell $(2-3 \mathrm{~nm})$. Enhancing the diffusion rate of an active molecule into the empty core domain is sometimes required, for example, by using highpressure supercritical fluid [35, 36] and vacuum-impregnation techniques [17]. A particular challenge with the post-loading approach is the incorporation of water-soluble molecules for sustained-release applications, as the adsorption of active molecules onto the nanocapsule's outer surfaces lead to undesirable initial burst release.

\section{Fig. 9}

\subsection{Pre-loading approach}

An alternative strategy is to adopt a pre-loading strategy, in which active molecules are encapsulated in the core template prior to silica-shell formation (Fig. 10). Pre-loading can be achieved by adsorbing active molecules within a porous particle (i.e., hard template) that can be subsequently coated with a silica shell (Fig. 10A). This technique depends on the high surface area and pore volume of the porous nanoparticle accommodating the adsorption capacity of the active molecules. Sacrificial templates, such as calcium carbonate nanoparticles [37, 38], can be removed using conditions that do not significantly affect the activity of the loaded active molecules. Perhaps one of the most versatile techniques for encapsulating active molecules involves solubilizing or dispersing active molecules in the template materials (i.e., liquid template) prior to the formation of silica shells (Fig. 10B). Hydrophobic and hydrophilic active molecules can be incorporated into $\mathrm{O} / \mathrm{W}$ and $\mathrm{W} / \mathrm{O}$ emulsion-templated silica nanocapsules, respectively. This approach affords a high loading capacity by judiciously selecting appropriate active molecules and template components. It is applicable to a range of materials of different sizes from enzymes (e.g., horseradish peroxidase [68] and superoxide 
dismutase/catalase [69]) to small molecular weight agrochemicals (e.g., fipronil [60, 61] and tebuconazole [59]), drugs (e.g., ibuprofen [72]), and organic dyes (e.g., rhodamine B thioisocyanate [72] and pyrene [49]). Pre-loading of these active molecules reduces the possibility of their adsorption at the external surfaces of the shells, thus increasing the flexibility to protect and release the cargo, which is essential in controlled-release applications.

\section{Fig. 10}

\section{Applications of silica nanocapsules}

The following section will address the development of functional silica nanocapsules as controlled release nanocarriers, imaging/diagnostic agents, and both therapeutic and diagnostic agents (theranostics).

\subsection{Controlled release}

A variety of nanocarriers for the delivery and controlled release of active molecules has been developed in the past decades, including lipid (e.g., liposomes, phospholipid micelles, solid lipid nanoparticles, etc.) and polymer (e.g., polymersomes, polymeric micelles, polymeric nanoparticles, etc.) based nanocarriers. Silica nanocapsules as an inorganic nanocarrier represent a very promising type of controlled release vehicle due to their core-shell structure and the physicochemical properties of silica (e.g., high chemical and mechanical stability and easy functionalization) (Table 4). Compared to nanoparticle carriers in which the active molecules are incorporated by either covalent conjugation to their surface or physical entrapment in the cross-linked particles, the inner-core space of silica nanocapsules allows higher encapsulation capacity. Furthermore, the type of components encapsulated in the core is not limited to only hydrophobic (as in micelle-structured nanocarriers) or hydrophilic (as in vesicle-structured nanocarriers) cargoes, but can also be both hydrophobic and hydrophilic, highlighting the versatility of silica nanocapsules. Additionally, the tunable thicknesses, pore sizes and pore structures of the silica shells allows easy control over the release kinetics (Tables 
2-4) $[17,22,60,61,109]$. The controlled-release coupled with high-loading and shell-stability features of silica nanocapsules are important, for example, in agricultural applications [61] where an effective local concentration of encapsulated toxic pesticides should be maintained in a prolonged duration to minimize potential for development of pest resistance and adverse environmental effects. Furthermore, sustained release of active molecules from silica nanocapsules can be engineered to have specific stepped release behavior [111, 112], which may find applications in skin protection, transdermal therapy and tissue regeneration.

\section{Table 4}

In order to minimize premature and non-specific release of the cargo, silica nanocapsules can either be capped with environmentally-sensitive moieties as gatekeepers or be filled with chemical-sensitive materials (Table 4). Release of the encapsulated cargo from silica nanocapsules can then be activated by chemical (e.g., acid/base [32, 108, 109], salts [109], and biomolecules [20]) or physical (e.g., light [113] and magnetic field [33, 114]) triggers to achieve the desired controlled and predictable release. $\mathrm{pH}$ stimulus to trigger cargo release is widely utilized, since the $\mathrm{pH}$ within the body and biological cells has been well known, thus controlled cargo-release in a particular organ on the basis of $\mathrm{pH}$ is conceptually easy. Supramolecular systems composed of $\alpha$-cyclodextrin/aniline have been used as $\mathrm{pH}$-responsive materials functionalized on the surface of propidium iodide-loaded hollow silica nanoparticles (Fig. 11A) [108]. At neutral pH, the aniline nitrogen was not protonated and was encircled by the $\alpha$-cyclodextrin rings that blocked the pores thus retaining the cargo molecules inside the cavity of the hollow nanoparticles. Upon decreasing $\mathrm{pH}$, protonation of the nitrogen caused the $\alpha$-cyclodextrin to dissociate, unblock the pores and then release the loaded cargo molecules from the interior. An ultraviolet (UV) light-stimulated gatekeeper system composed of amphiphilic copolymer with Azo-functional groups has been used to bind to the $\beta$ cyclodextrin-modified hollow silica nanoparticles to form light-responsive nanocarriers (Fig. 
11B) [113]. During UV-light irradiation, the isomerism of the Azo groups was transformed from trans to cis conformation which resulted in unbinding of the copolymer from the surfaces hence activating the release of encapsulated ibuprofen drug through the silica shell. When the UV light was switched to visible (Vis) light, trans-Azo reverted to cis-Azo and made the copolymer bound to the $\beta$-cyclodextrin-modified hollow silica nanoparticles thus closing the shell diffusional pathway. Another controlled-release silica-based nanocarrier sensitive to reduction-oxidation reaction (redox) has also been utilized. Redox-responsive nanocapsules were demonstrated by functionalizing the nanocapsules with a capping agent $\alpha$-cyclodextrinbased [2]rotaxane (Fig. 11C) [20]. Adding a reducing agent (glutathione (GSH)) resulted in cleavage of the disulfide bond that links $\alpha$-cyclodextrin-based [2]rotaxane with the nanocapsule surface due to its reducibility, thus leading to the removal of the capping agent from the nanocapsule surface for quick cargo release. Magnetic field-responsive silica-based nanocarriers have also been reported, thereby using magnetic nanoparticles $\left(\mathrm{Fe}_{3} \mathrm{O}_{4}\right)$-filled silica nanocapsules [33, 114]. The controlled release of drug molecules (i.e., camptothecin or doxorubicin) from silica nanocapsules containing $\mathrm{Fe}_{3} \mathrm{O}_{4}$ have been investigated by applying an external radio frequency (RF) magnetic field in the form of on-off cycles (Fig. 11D) [33]. The $\mathrm{RF}$ magnetic field elevated the temperature of $\mathrm{Fe}_{3} \mathrm{O}_{4}$ inside the core and thus created a temperature gradient between the inner and outer space of the nanocapsule which stimulated accelerated diffusion of the drug out from the nanocapsule through the shell.

\section{Fig. 11}

\subsection{Imaging}

To date, various types of imaging probes have been encapsulated into or functionalized onto silica nanocapsules to gain imaging functionalities. Several imaging modalities have been utilized to enable silica nanocapsules for fluorescence imaging, magnetic resonance imaging (MRI), ultrasound imaging, positron emission tomography (PET), and multimodal imaging. 
Silica nanocapsules in imaging have been mainly focusing on biomedical applications, especially for studying biodistribution and monitoring molecular/biological events in cells and animal models such as cell-targeting efficiency, internalization pathways, cytotoxicity, and therapy progress. Compared to lipid and polymeric nanocarriers, silica nanocapsules provide a more chemically and mechanically stable shell to confine and protect imaging agents at the core thus minimizing the probability of leaching, quenching (due to interaction with neighboring agents), and photobleaching (due to interaction with soluble oxygen molecules) under biological conditions. Also, the silica shell can be easily functionalized for targeting delivery of the imaging agents. This stable and functional silica shell synergistically ensures the imaging agents are maintained in silica nanocapsules during trafficking to the target cells and imaging with enhanced image contrast. However, the stability of silica nanocapsules in vivo during post imaging requires further investigation to determine their biodegradability, long-term toxicity, and clearance from the body.

Silica nanocapsules can either be loaded or surface-functionalized with quantum dots (e.g., CdSe [64]) or fluorescent dyes (e.g., fluorescein isothiocyanate [31, 58, 64], rhodamine B isothiocyanate [58], nile red [64], coumarin blue dye [57], and near-IR dyes [16]) for creating colorimetric contrast in fluorescence imaging. Another relatively new method of using silica nanocapsules for imaging is in the field of magnetic resonance imaging (MRI) using a contrast agent, with its contrast translated from the electromagnetic signal of the relaxation of water protons (i.e., longitudinal $\left(T_{1}\right)$ or transverse $\left(T_{2}\right)$ relaxation) sourced from external magnetic field and radio-frequency pulse. Silica nanocapsules can be used to incorporate magnetic nanoparticles (e.g., $\mathrm{Fe}_{3} \mathrm{O}_{4}$ [64]) in the core domain for efficient $T_{2}$-weighted MRI, while functionalizing the surfaces of silica nanocapsules with $\mathrm{MnO}$ [19] or gadolinium complex [64, 70] is effective for $T_{1}$-weighted MRI by increasing the signal differences between tissues, thus improving the accuracy of MRI images. Integration of fluorescent and MR in silica 
nanocapsules is a way to produce a bimodal bioimaging probe which combines the merits of fluorescence imaging (i.e., inexpensive, widely available, and highly sensitive for superficial tissues) and MRI (i.e., non-invasive and has high spatial resolution for anatomical images and detection of cancerous tissues) [64, 70, 115]. For example, Santra et al. [70] reported the synthesis of a silica nanocapsule wherein ruthenium-based compound was encapsulated in the core and gadolinium complex was functionalized to the inner surface of the silica shell to provide fluorescence imaging and $T_{2}$-weighted MRI, respectively. MRI can also be combined with ultrasound imaging using a single silica nanocapsule through surface-functionalizing with $\mathrm{MnO}$ and encapsulating perfluorohexane into the nanocapsule to yield a bimodal bioimaging probe where MRI can potentially be employed as the pre-surgical evaluation tool and ultrasound can be exploited for real-time guidance during high-intensity focused ultrasound (HIFU) therapy [19, 21]. Moreover, dual-modality imaging has also been demonstrated to take advantages of both PET (i.e., highly sensitive, quantitative, non-invasive, and has high-signal tissue penetration) and fluorescent imaging by labelling silica nanocapsules with positronemitting radionuclide ${ }^{64} \mathrm{Cu}$ and near-IR dye ZW800, respectively [16].

\subsection{Theranostics}

Recently, the development of silica nanocapsules with multiple functionalities have gained significant research interest for biomedical applications [15-17, 20, 21, 32, 103, 116]. Silica nanocapsules can be designed as an excellent nanotheranostic probe combining therapy and diagnostic/imaging functionalities in order to efficiently deliver therapeutic agents for specific disease while at the same time tracking the location of nanocapsules and monitoring the evolution of the disease. Diverse therapeutic and imaging agents have been incorporated into silica nanocarrier platform in various ways, including encapsulation in the inner cavity and conjugation to the surface of the silica shell. In addition, PEG is commonly used to coat silica nanocapsules in order to provide a protective barrier enhancing their dispersion and stability in 
biological fluids, thus increasing their bioavailability and hence circulation times in vivo. To enhance the performance of silica nanocapsules, targeting molecules (e.g., antibody [16, 32] and folic acid [20]) can be functionalized onto the nanocapsules' surface to deliver the encapsulated therapeutic agent directly to the targeted tumor cells. This is especially important when encapsulating, for example, anticancer drugs which may have serious side-effects owing to their non-specific actions on healthy cells and tissues.

The integration of multiple functionalities makes it possible to use silica nanocapsules for simultaneous imaging and targeted therapy. Cai et al. synthesized multifunctional hollow mesoporous silica nanoparticle (HMSN) for targeting tumor vasculature in vivo (Fig. 12) [16]. An anticancer drug doxorubicin was loaded in the core domain (Fig. 12A), in which HMSN demonstrated higher drug loading capacity than mesoporous silica nanoparticles. The silica shell was functionalized with PEG, PET imaging agent (i.e., ${ }^{64} \mathrm{Cu}$ ), and targeting molecule (i.e., thiolated anti-CD105 antibody, TRC105). This nanocapsular system also showed pHresponsive behaviour; lowering the solution $\mathrm{pH}$ led to the protonation of silanol groups on the silica shell and decreased the electrostatic interaction between doxorubicin and the silica shell resulting in the dissociation of doxorubicin from both the silica outer surface and the mesoporous channels (Fig. 12B). When the multifunctional HMSN was injected intravenously into 4T1 tumor-bearing mice (Fig. 12C), the HMSN accumulated dominantly in the targeted tumor with the optical signal significantly higher than the control group which did not have the targeting molecule conjugated on the surface (Fig. 12D).

\section{Fig. 12}

\section{Conclusions and outlook}

Significant progress has been accomplished for the development of silica nanocapsules in the past decades, as described in this review. Templating approaches utilize hard (i.e., solid nanoparticles) and soft (i.e., emulsion droplets and gas bubbles) templates comprising surface 
functional groups that are receptive to silica species, hence enabling the formation of silica exclusively at solid-liquid, liquid-liquid, and gas-liquid interfaces. Despite their wide utilities, hard template-based approaches suffer from inherent difficulties, such as harsh conditions for template removal and limited cargo diffusion into the hollow silica nanocapsules (i.e., postloading approach). These difficulties can be partly overcome by use of soft templates which allow facile and efficient cargo encapsulation by solubilizing the cargo directly in the liquid template prior to silica growth (i.e., pre-loading approach). Overall, a large number of cargoes, including therapeutics, agrochemicals and imaging/contrast agents, have been encapsulated in silica nanocapsules. Silica chemistry of the resultant silica nanocapsules is versatile, thus enabling surface functionalization with a variety of functional active molecules including targeting molecules, stimuli-responsive materials, polymer coat, and imaging/contrast agents. The surface engineering is a feasible way to make multifunctional silica nanocapsules as well as to enable prevention of cargo loss due to leakage or burst release, thus making the silica nanocapsules a robust nanocarrier platform with controlled and predictable release, imaging, and theranostic (therapy and diagnosis) functionalities.

The properties of silica nanocapsules depend not only on the intrinsic properties of silica, but also on other factors such as the synthesis processes and the possible residues from the components used during the synthesis process. So their safety and biocompatibility need to be carefully characterized, especially for biomedical applications. Because of the intrinsically benign properties of silica, most silica nanocapsules demonstrated low toxicity against different cell lines [14, 20, 22, 28, 31-33, 64] and did not cause hemolysis [14, 116-118]. In vivo toxicity studies on hollow mesoporous silica nanoparticles also suggested low toxicity with neither noticeable organ damage nor inflammation [117]. Single or repeated administrations of hollow mesoporous silica nanoparticles through intravenous injection in mice also showed low toxicity (also depending on the dosages), and the clearance time was estimated to be over a month 
[118]. But some silica nanocapsules have been found cytotoxic mainly because of the residual chemical surfactants especially ionic-type surfactants $[119,120]$. So, the interactions between silica nanocapsules with biological systems at the nano-bio interfaces are multifactorial depending on dosages, administration routes, media compositions and nanocapsule properties, thus their safety properties should be investigated carefully on a case-by-case basis. Different synthetic routes toward silica nanocapsules can result in different physicochemical characteristics of the final silica nanocapsules (i.e., size, shape, porosity, crystallinity, composition, surface charge (type and density) and surface chemistry), which could influence their behavior and performance at molecular, cellular and organ levels.

Large scale synthesis of silica nanocapsules for practical applications is possible but challenging, mainly depending on the process for making silica nanocapsules. Cheap raw materials and simple fabrication process are essential for large scale production. Multiple steps involved in hard-templating methods, especially the template-removal processes, make them difficult to form silica nanocapsules with well controlled properties in a large scale. The gas bubble-templating methods seem simple as template-removal steps are avoided, but batch-tobatch variations of the physicochemical properties of resultant silica nanocapsules due to the polydisperse nature of formed bubbles make the quality controls of the final products difficult. The emulsion templating approach may potentially be feasible for large scale synthesis of silica nanocapsules as the template removal steps can be avoided if biocompatible emulsions are used as the template. To ensure silica nanocapsules composed of biocompatible materials, emulsion templating methods can be combined with biomimetic mineralization approaches through the utility of designer biological molecules such as peptides and proteins, in lieu of conventional chemical surfactants, to facilitate formation and stabilization of emulsions and concurrently induce silica mineralization at the interfaces forming silica nanocapsules. Advantages offered by these mineralizing biomolecules include the ability to be genetically engineered and 
produced renewably in microbial cell factories, and the possibility for scale-up at a relatively low cost using established bioprocess unit operations.

Future research focus in silica nanocapsules will include simple and facile approaches for making multifunctional nanocarriers with minimum cargo loss and, more importantly, using non-toxic components and processes that would not require tedious monitoringprocedures for ensuring complete removal of residual toxic components down to the levels that might be considered environmentally or biomedically safe. Furthermore, the performance of the resultant nanocapsules needs to be evaluated by conducting in vivo studies using biological models and subsequent translational experiments.

\section{Acknowledgments}

The authors acknowledge the research funding by the Australian Research Council (ARC) under Discovery Project (DP150100798) and Future Fellowship Project (FT140100726). C.X.Z. acknowledges financial support from the award of the ARC Future Fellowship (FT140100726). Y.H. acknowledges PhD scholarships from the University of Queensland and the Chinese Scholarship Council.

\section{References}

[1] Lou XW, Archer LA, Yang Z. Hollow micro-/nanostructures: synthesis and applications. Adv Mater 2008;20:3987-4019.

[2] Liu J, Liu F, Gao K, Wu J, Xue D. Recent developments in the chemical synthesis of inorganic porous capsules. J Mater Chem 2009;19:6073-84.

[3] Schärtl W. Current directions in core-shell nanoparticle design. Nanoscale 2010;2:829-43.

[4] Chatterjee K, Sarkar S, Jagajjanani Rao K, Paria S. Core/shell nanoparticles in biomedical applications. Adv Colloid Interface Sci 2014;209:8-39. 
[5] Cui J, van Koeverden MP, Müllner M, Kempe K, Caruso F. Emerging methods for the fabrication of polymer capsules. Adv Colloid Interface Sci 2014;207:14-31.

[6] Li Y, Shi J. Hollow-structured mesoporous materials: chemical synthesis, functionalization and applications. Adv Mater 2014;26:3176-205.

[7] Vert M, Doi Y, Hellwich KH, Hess M, Hodge P, Kubisa P, Rinaudo M, Schue F. Terminology for biorelated polymers and applications (IUPAC Recommendations 2012). Pure Appl Chem 2012;84:377-408.

[8] Guerrero-Martínez A, Pérez-Juste J, Liz-Marzán LM. Recent progress on silica coating of nanoparticles and related nanomaterials. Adv Mater 2010;22:1182-95.

[9] Chen Y, Xu P, Chen H, Li Y, Bu W, Shu Z, Li Y, Zhang J, Zhang L, Pan L, Cui X, Hua Z, Wang J, Zhang L, Shi J. Colloidal HPMO nanoparticles: silica-etching chemistry tailoring, topological transformation, and nano-biomedical applications. Adv Mater 2013;25:3100-5.

[10] Zhang Y, Hsu BYW, Ren C, Li X, Wang J. Silica-based nanocapsules: synthesis, structure control and biomedical applications. Chem Soc Rev 2015;44:315-35.

[11] Liu JN, Bu WB, Shi JL. Silica coated upconversion nanoparticles: a versatile platform for the development of efficient theranostics. Acc Chem Res 2015;48:1797-805.

[12] U.S. Food and Drug Administration. GRN No. 321: Synthetic amorphous silica. Last Updated: 30/11/2015. Last Accessed: 4/3/2016. URL: http://www.accessdata.fda.gov/scripts/fdcc/?set=GRASNotices\&id=321

[13] Chen Y, Chen H, Shi J. In vivo bio-safety evaluations and diagnostic/therapeutic applications of chemically designed mesoporous silica nanoparticles. Adv Mater 2013;25:3144-76.

[14] Chen Y, Chen H, Guo L, He Q, Chen F, Zhou J, Feng J, Shi J. Hollow/rattle-type mesoporous nanostructures by a structural difference-based selective etching strategy. ACS Nano 2010;4:529-39. 
[15] Chen Y, Gao Y, Chen H, Zeng D, Li Y, Zheng Y, Li F, Ji X, Wang X, Chen F, He Q, Zhang L, Shi J. Engineering inorganic nanoemulsions/nanoliposomes by fluoride-silica chemistry for efficient delivery/co-delivery of hydrophobic agents. Adv Funct Mater 2012;22:1586-97.

[16] Chen F, Hong H, Shi S, Goel S, Valdovinos HF, Hernandez R, Theuer CP, Barnhart TE, Cai W. Engineering of hollow mesoporous silica nanoparticles for remarkably enhanced tumor active targeting efficacy. Sci Rep 2014;4:1-10.

[17] Chen Y, Chu C, Zhou Y, Ru Y, Chen H, Chen F, He Q, Zhang Y, Zhang L, Shi J. Reversible pore-structure evolution in hollow silica nanocapsules: large pores for siRNA delivery and nanoparticle collecting. Small 2011;7:2935-44.

[18] Mahony D, Cavallaro AS, Mody KT, Xiong L, Mahony TJ, Qiao SZ, Mitter N. In vivo delivery of bovine viral diahorrea virus, E2 protein using hollow mesoporous silica nanoparticles. Nanoscale 2014;6:6617-26.

[19] Chen Y, Chen HR, Sun Y, Zheng YY, Zeng DP, Li FQ, Zhang SJ, Wang X, Zhang K, Ma M, He QJ, Zhang LL, Shi JL. Multifunctional mesoporous composite nanocapsules for highly efficient MRI-guided high-intensity focused ultrasound cancer surgery. Angew Chem Int Ed 2011;50:12505-9.

[20] Luo Z, Ding X, Hu Y, Wu S, Xiang Y, Zeng Y, Zhang B, Yan H, Zhang H, Zhu L, Liu J, Li J, Cai K, Zhao Y. Engineering a hollow nanocontainer platform with multifunctional molecular machines for tumor-targeted therapy in vitro and in vivo. ACS Nano 2013;7:1027184.

[21] Wang X, Chen HR, Chen Y, Ma M, Zhang K, Li FQ, Zheng YY, Zeng DP, Wang Q, Shi JL. Perfluorohexane-encapsulated mesoporous silica nanocapsules as enhancement agents for highly efficient high intensity focused ultrasound (HIFU). Adv Mater 2012;24:78591. 
[22] Gao Y, Chen Y, Ji X, He X, Yin Q, Zhang Z, Shi J, Li Y. Controlled intracellular release of doxorubicin in multidrug-resistant cancer cells by tuning the shell-pore sizes of mesoporous silica nanoparticles. ACS Nano 2011;5:9788-98.

[23] Zhao W, Lang M, Li Y, Li L, Shi J. Fabrication of uniform hollow mesoporous silica spheres and ellipsoids of tunable size through a facile hard-templating route. J Mater Chem 2009;19:2778-83.

[24] Zheng M, Cao J, Chang X, Wang J, Liu J, Ma X. Preparation of oxide hollow spheres by colloidal carbon spheres. Mater Lett 2006;60:2991-3.

[25] Wang Y, Wang K, Zhang R, Liu X, Yan X, Wang J, Wagner E, Huang R. Synthesis of core-shell graphitic carbon@silica nanospheres with dual-ordered mesopores for cancertargeted photothermochemotherapy. ACS Nano 2014;8:7870-9.

[26] Zhang $\mathrm{H}, \mathrm{Xu} \mathrm{H}, \mathrm{Wu}$ M, Zhong Y, Wang D, Jiao Z. A soft-hard template approach towards hollow mesoporous silica nanoparticles with rough surfaces for controlled drug delivery and protein adsorption. J Mater Chem B 2015;3:6480-9.

[27] Chen Y, Kang ET, Neoh KG, Greiner A. Preparation of hollow silica nanospheres by surface-initiated atom transfer radical polymerization on polymer latex templates. Adv Funct Mater 2005;15:113-7.

[28] Jiao Y, Guo J, Shen S, Chang B, Zhang Y, Jiang X, Yang W. Synthesis of discrete and dispersible hollow mesoporous silica nanoparticles with tailored shell thickness for controlled drug release. J Mater Chem 2012;22:17636-43.

[29] Cornelissen JJLM, Connor EF, Kim HC, Lee VY, Magibitang T, Rice PM, Volksen W, Sundberg LK, Miller RD. Versatile synthesis of nanometer sized hollow silica spheres. Chem Commun 2003:1010-1. 
[30] Qi G, Wang Y, Estevez L, Switzer AK, Duan X, Yang X, Giannelis EP. Facile and scalable synthesis of monodispersed spherical capsules with a mesoporous shell. Chem Mater 2010;22:2693-5.

[31] Shen J, Song G, An M, Li X, Wu N, Ruan K, Hu J, Hu R. The use of hollow mesoporous silica nanospheres to encapsulate bortezomib and improve efficacy for non-small cell lung cancer therapy. Biomaterials 2014;35:316-26.

[32] Deng Z, Zhen Z, Hu X, Wu S, Xu Z, Chu PK. Hollow chitosan-silica nanospheres as pH-sensitive targeted delivery carriers in breast cancer therapy. Biomaterials 2011;32:497686.

[33] Kong SD, Zhang W, Lee JH, Brammer K, Lal R, Karin M, Jin S. Magnetically vectored nanocapsules for tumor penetration and remotely switchable on-demand drug release. Nano Lett 2010;10:5088-92.

[34] Chen JF, Ding HM, Wang JX, Shao L. Preparation and characterization of porous hollow silica nanoparticles for drug delivery application. Biomaterials 2004;25:723-7.

[35] Li ZZ, Xu SA, Wen LX, Liu F, Liu AQ, Wang Q, Sun HY, Yu W, Chen JF. Controlled release of avermectin from porous hollow silica nanoparticles: influence of shell thickness on loading efficiency, UV-shielding property and release. J Control Release 2006;111:81-8.

[36] Liu F, Wen LX, Li ZZ, Yu W, Sun HY, Chen JF. Porous hollow silica nanoparticles as controlled delivery system for water-soluble pesticide. Mater Res Bull 2006;41:2268-75.

[37] Zhao Y, Lin LN, Lu Y, Chen SF, Dong L, Yu SH. Templating synthesis of preloaded doxorubicin in hollow mesoporous silica nanospheres for biomedical applications. Adv Mater 2010;22:5255-9.

[38] Zhao Y, Luo Z, Li M, Qu Q, Ma X, Yu SH, Zhao Y. A preloaded amorphous calcium carbonate/doxorubicin@silica nanoreactor for pH-responsive delivery of an anticancer drug. Angew Chem Int Ed 2015;54:919-22. 
[39] Williamson PA, Blower PJ, Green MA. Synthesis of porous hollow silica nanostructures using hydroxyapatite nanoparticle templates. Chem Commun 2011;47:156870.

[40] Lu Y, McLellan J, Xia Y. Synthesis and crystallization of hybrid spherical colloids composed of polystyrene cores and silica shells. Langmuir 2004;20:3464-70.

[41] Zhang T, Ge J, Hu Y, Zhang Q, Aloni S, Yin Y. Formation of hollow silica colloids through a spontaneous dissolution-regrowth process. Angew Chem Int Ed 2008;47:5806-11. [42] Ji Q, Guo C, Yu X, Ochs CJ, Hill JP, Caruso F, Nakazawa H, Ariga K. Flake-shell capsules: adjustable inorganic structures. Small 2012;8:2345-9.

[43] Ji Q, Hill JP, Ariga K. Shell-adjustable hollow 'soft' silica spheres as a support for gold nanoparticles. J Mater Chem A 2013;1:3600-6.

[44] Terentyeva TG, Matras A, Van Rossom W, Hill JP, Ji Q, Ariga K. Bioactive flake-shell capsules: soft silica nanoparticles for efficient enzyme immobilization. J Mater Chem B 2013;1:3248-56.

[45] Caruso F, Caruso RA, Möhwald H. Nanoengineering of inorganic and hybrid hollow spheres by colloidal templating. Science 1998;282:1111-4.

[46] Caruso F, Möhwald H. Preparation and characterization of ordered nanoparticle and polymer composite multilayers on colloids. Langmuir 1999;15:8276-81.

[47] Caruso RA, Susha A, Caruso F. Multilayered titania, silica, and laponite nanoparticle coatings on polystyrene colloidal templates and resulting inorganic hollow spheres. Chem Mater 2001;13:400-9.

[48] Caruso F. Nanoengineering of particle surfaces. Adv Mater 2001;13:11-22.

[49] Chen H, He J, Tang H, Yan C. Porous silica nanocapsules and nanospheres: dynamic self-assembly synthesis and application in controlled release. Chem Mater 2008;20:5894-900. 
[50] Li J, Liu J, Wang D, Guo R, Li X, Qi W. Interfacially controlled synthesis of hollow mesoporous silica spheres with radially oriented pore structures. Langmuir 2010;26:1226772.

[51] Teng Z, Han Y, Li J, Yan F, Yang W. Preparation of hollow mesoporous silica spheres by a sol-gel/emulsion approach. Microporous Mesoporous Mater 2010;127:67-72.

[52] Zhao Y, Zhang J, Li W, Zhang C, Han B. Synthesis of uniform hollow silica spheres with ordered mesoporous shells in a $\mathrm{CO}_{2}$ induced nanoemulsion. Chem Commun 2009:23657.

[53] Underhill RS, Jovanovic AV, Carino SR, Varshney M, Shah DO, Dennis DM, Morey TE, Duran RS. Oil-filled silica nanocapsules for lipophilic drug uptake: implications for drug detoxification therapy. Chem Mater 2002;14:4919-25.

[54] Jovanovic AV, Underhill RS, Bucholz TL, Duran RS. Oil core and silica shell nanocapsules: toward controlling the size and the ability to sequester hydrophobic compounds. Chem Mater 2005;17:3375-83.

[55] Zhao M, Zheng L, Bai X, Li N, Yu L. Fabrication of silica nanoparticles and hollow spheres using ionic liquid microemulsion droplets as templates. Colloids Surf A Physicochem Eng Asp 2009;346:229-36.

[56] Chin LS, Lim M, Hung TT, Marquis CP, Amal R. Perfluorodecalin nanocapsule as an oxygen carrier and contrast agent for ultrasound imaging. RSC Adv 2014;4:13052-60.

[57] Attia MF, Anton N, Bouchaala R, Didier P, Arntz Y, Messaddeq N, Klymchenko AS, Mely Y, Vandamme TF. Functionalization of nano-emulsions with an amino-silica shell at the oil-water interface. RSC Adv 2015;5:74353-61.

[58] Tsou CJ, Chu Cy, Hung Y, Mou CY. A broad range fluorescent pH sensor based on hollow mesoporous silica nanoparticles, utilising the surface curvature effect. J Mater Chem B 2013;1:5557-63. 
[59] Qian K, Shi T, He S, Luo L, liu X, Cao Y. Release kinetics of tebuconazole from porous hollow silica nanospheres prepared by miniemulsion method. Microporous Mesoporous Mater 2013;169:1-6.

[60] Wibowo D, Zhao CX, Middelberg APJ. Emulsion-templated silica nanocapsules formed using bio-inspired silicification. Chem Commun 2014;50:11325-8.

[61] Wibowo D, Zhao CX, Peters BC, Middelberg APJ. Sustained release of fipronil insecticide in vitro and in vivo from biocompatible silica nanocapsules. J Agric Food Chem 2014;62:12504-11.

[62] Hui Y, Wibowo D, Zhao C-X. Insights into the role of biomineralizing peptide surfactants on making nanoemulsion-templated silica nanocapsules. Langmuir 2016;32:82230.

[63] Wibowo D, Zhao CX, Middelberg APJ. Interfacial biomimetic synthesis of silica nanocapsules using a recombinant catalytic modular protein. Langmuir 2015;31:1999-2007. [64] Jakhmola A, Vecchione R, Guarnieri D, Belli V, Calabria D, Netti PA. Bioinspired oil core/silica shell nanocarriers with tunable and multimodal functionalities. Adv Healthc Mater 2015;4:2688-98.

[65] Lin YS, Wu SH, Tseng CT, Hung Y, Chang C, Mou CY. Synthesis of hollow silica nanospheres with a microemulsion as the template. Chem Commun 2009:3542-4.

[66] Jatupaiboon N, Wang Y, Wu H, Song X, Song Y, Zhang J, Ma X, Tan M. A facile microemulsion template route for producing hollow silica nanospheres as imaging agents and drug nanocarriers. J Mater Chem B 2015;3:3130-3.

[67] Cao Z, Dong L, Li L, Shang Y, Qi D, Lv Q, Shan G, Ziener U, Landfester K. Preparation of mesoporous submicrometer silica capsules via an interfacial sol-gel process in inverse miniemulsion. Langmuir 2012;28:7023-32. 
[68] Chang FP, Hung Y, Chang JH, Lin CH, Mou CY. Enzyme encapsulated hollow silica nanospheres for intracellular biocatalysis. ACS Appl Mater Interfaces 2014;6:6883-90.

[69] Chang FP, Chen YP, Mou CY. Intracellular implantation of enzymes in hollow silica nanospheres for protein therapy: cascade system of superoxide dismutase and catalase. Small 2014;10:4785-95.

[70] Santra S, Bagwe RP, Dutta D, Stanley JT, Walter GA, Tan W, Moudgil BM, Mericle RA. Synthesis and characterization of fluorescent, radio-opaque, and paramagnetic silica nanoparticles for multimodal bioimaging applications. Adv Mater 2005;17:2165-9.

[71] Wu S-H, Hung Y, Mou C-Y. Compartmentalized hollow silica nanospheres templated from nanoemulsions. Chem Mater 2013;25:352-64.

[72] Hayashi K, Nakamura M, Ishimura K. In situ synthesis and photoresponsive rupture of organosilica nanocapsules. Chem Commun 2011;47:1518-20.

[73] Yu X, Liang F, Liu J, Lu Y, Yang Z. Mesoporous hollow spheres from soap bubbling. J Colloid Interface Sci 2012;367:531-6.

[74] Yue Q, Li Y, Kong M, Huang J, Zhao X, Liu J, Williford RE. Ultralow density, hollow silica foams produced through interfacial reaction and their exceptional properties for environmental and energy applications. J Mater Chem 2011;21:12041-6.

[75] Rana RK, Mastai Y, Gedanken A. Acoustic cavitation leading to the morphosynthesis of mesoporous silica vesicles. Adv Mater 2002;14:1414-8.

[76] Prouzet E, Cot F, Boissiere C, Kooyman PJ, Larbot A. Nanometric hollow spheres made of MSU-X-type mesoporous silica. J Mater Chem 2002;12:1553-6.

[77] Wang JG, Li F, Zhou HJ, Sun PC, Ding DT, Chen TH. Silica hollow spheres with ordered and radially oriented amino-functionalized mesochannels. Chem Mater 2009;21:61220. 
[78] Brinker CJ. Hydrolysis and condensation of silicates: effects on structure. J Non-Cryst Solids 1988;100:31-50.

[79] Chen Y, Meng Q, Wu M, Wang S, Xu P, Chen H, Li Y, Zhang L, Wang L, Shi J. Hollow mesoporous organosilica nanoparticles: a generic intelligent framework-hybridization approach for biomedicine. J Am Chem Soc 2014;136:16326-34.

[80] Li X, Yang Y, Yang Q. Organo-functionalized silica hollow nanospheres: synthesis and catalytic application. J Mater Chem A 2013;1:1525-35.

[81] Croissant JG, Cattoen X, Man MWC, Durand J-O, Khashab NM. Syntheses and applications of periodic mesoporous organosilica nanoparticles. Nanoscale 2015;7:20318-34. [82] Hoffmann F, Cornelius M, Morell J, Fröba M. Silica-based mesoporous organicinorganic hybrid materials. Angew Chem Int Ed 2006;45:3216-51.

[83] Stöber W, Fink A, Bohn E. Controlled growth of monodisperse silica spheres in the micron size range. J Colloid Interface Sci 1968;26:62-9.

[84] Wan Y, Zhao. On the controllable soft-templating approach to mesoporous silicates. Chem Rev 2007;107:2821-60.

[85] Cha JN, Shimizu K, Zhou Y, Christiansen SC, Chmelka BF, Stucky GD, Morse DE. Silicatein filaments and subunits from a marine sponge direct the polymerization of silica and silicones in vitro. Proc Natl Acad Sci 1999;96:361-5.

[86] Zhou Y, Shimizu K, Cha JN, Stucky GD, Morse DE. Efficient catalysis of polysiloxane synthesis by silicatein a requires specific hydroxy and imidazole functionalities. Angew Chem Int Ed 1999;38:779-82.

[87] Kröger N, Deutzmann R, Sumper M. Polycationic peptides from diatom biosilica that direct silica nanosphere formation. Science 1999;286:1129-32.

[88] Knecht MR, Wright DW. Functional analysis of the biomimetic silica precipitating activity of the R5 peptide from Cylindrotheca fusiformis. Chem Commun 2003:3038-9. 
[89] Naik RR, Brott LL, Clarson SJ, Stone MO. Silica-precipitating peptides isolated from a combinatorial phage display peptide library. J Nanosci Nanotechnol 2002;2:95-100.

[90] Altunbas A, Sharma N, Lamm MS, Yan CQ, Nagarkar RP, Schneider JP, Pochan DJ. Peptide-silica hybrid networks: biomimetic control of network mechanical behavior. ACS Nano 2010;4:181-8.

[91] Cha JN, Stucky GD, Morse DE, Deming TJ. Biomimetic synthesis of ordered silica structures mediated by block copolypeptides. Nature 2000;403:289-92.

[92] Dickerson MB, Sandhage KH, Naik RR. Protein- and peptide-directed syntheses of inorganic materials. Chem Rev 2008;108:4935-78.

[93] Chen C-L, Rosi NL. Peptide-based methods for the preparation of nanostructured inorganic materials. Angew Chem Int Ed 2010;49:1924-42.

[94] Patwardhan SV. Biomimetic and bioinspired silica: recent developments and applications. Chem Commun 2011;47:7567-82.

[95] Graf P, Mantion A, Haase A, Thünemann AF, Mašić A, Meier W, Luch A, Taubert A. Silicification of peptide-coated silver nanoparticles-a biomimetic soft chemistry approach toward chiral hybrid core-shell materials. ACS Nano 2011;5:820-33.

[96] Brott LL, Naik RR, Pikas DJ, Kirkpatrick SM, Tomlin DW, Whitlock PW, Clarson SJ, Stone MO. Ultrafast holographic nanopatterning of biocatalytically formed silica. Nature 2001;413:291-3.

[97] Dexter AF, Malcolm AS, Middelberg APJ. Reversible active switching of the mechanical properties of a peptide film at a fluid-fluid interface. Nat Mater 2006;5:502-6.

[98] Yuan JJ, Wan DC, Yang ZL. A facile method for the fabrication of thiol-functionalized hollow silica spheres. J Phys Chem C 2008;112:17156-60. 
[99] Niu DC, Li YS, Ma Z, Diao H, Gu JL, Chen HR, Zhao WR, Ruan ML, Zhang YL, Shi JL. Preparation of uniform, water-soluble, and multifunctional nanocomposites with tunable sizes. Adv Funct Mater 2010;20:773-80.

[100] Fickert J, Rupper P, Graf R, Landfester K, Crespy D. Design and characterization of functionalized silica nanocontainers for self-healing materials. J Mater Chem 2012;22:228691.

[101] Gao J, Chen J, Li X, Wang M, Zhang X, Tan F, Xu S, Liu J. Azide-functionalized hollow silica nanospheres for removal of antibiotics. J Colloid Interface Sci 2015;444:38-41.

[102] Jiang X, Brinker CJ. Aerosol-assisted self-assembly of single-crystal core/nanoporous shell particles as model controlled release capsules. J Am Chem Soc 2006;128:4512-3.

[103] Mohapatra S, Rout SR, Narayan R, Maiti TK. Multifunctional mesoporous hollow silica nanocapsules for targeted co-delivery of cisplatin-pemetrexed and MR imaging. Dalton Trans 2014;43:15841-50.

[104] Yang J, Lee J, Kang J, Lee K, Suh JS, Yoon HG, Huh YM, Haam S. Hollow silica nanocontainers as drug delivery vehicles. Langmuir 2008;24:3417-21.

[105] Zhu J, Tang J, Zhao L, Zhou X, Wang Y, Yu C. Ultrasmall, well-dispersed, hollow siliceous spheres with enhanced endocytosis properties. Small 2010;6:276-82.

[106] Kim J, Kim HS, Lee N, Kim T, Kim H, Yu T, Song IC, Moon WK, Hyeon T. Multifunctional uniform nanoparticles composed of a magnetite nanocrystal core and a mesoporous silica shell for magnetic resonance and fluorescence imaging and for drug delivery. Angew Chem Int Ed 2008;47:8438-41.

[107] Jovanovic AV, Flint JA, Varshney M, Morey TE, Dennis DM, Duran RS. Surface modification of silica core-shell nanocapsules: biomedical implications. Biomacromolecules 2006;7:945-9. 
[108] Du L, Liao S, Khatib HA, Stoddart JF, Zink JI. Controlled-access hollow mechanized silica nanocontainers. J Am Chem Soc 2009;131:15136-42.

[109] Zhu YF, Shi JL, Shen WH, Dong XP, Feng JW, Ruan ML, Li YS. Stimuli-responsive controlled drug release from a hollow mesoporous silica sphere/polyelectrolyte multilayer core-shell structure. Angew Chem Int Ed 2005;44:5083-7.

[110] Cheng K, Sun S. Recent advances in syntheses and therapeutic applications of multifunctional porous hollow nanoparticles. Nano Today 2010;5:183-96.

[111] Ji Q, Acharya S, Hill JP, Vinu A, Yoon SB, Yu J-S, Sakamoto K, Ariga K. Hierarchic nanostructure for auto-modulation of material release: mesoporous nanocompartment films. Adv Funct Mater 2009;19:1792-9.

[112] Ji Q, Miyahara M, Hill JP, Acharya S, Vinu A, Yoon SB, Yu J-S, Sakamoto K, Ariga K. Stimuli-free auto-modulated material release from mesoporous nanocompartment films. J Am Chem Soc 2008;130:2376-7.

[113] Mei X, Yang S, Chen D, Li N, Li H, Xu Q, Ge J, Lu J. Light-triggered reversible assemblies of azobenzene-containing amphiphilic copolymer with $\beta$-cyclodextrin-modified hollow mesoporous silica nanoparticles for controlled drug release. Chem Commun 2012;48:10010-2.

[114] Lu F, Popa A, Zhou S, Zhu JJ, Samia ACS. Iron oxide-loaded hollow mesoporous silica nanocapsules for controlled drug release and hyperthermia. Chem Commun 2013;49:114368.

[115] Tan H, Wang M, Yang CT, Pant S, Bhakoo KK, Wong SY, Chen ZK, Li X, Wang J. Silica nanocapsules of fluorescent conjugated polymers and superparamagnetic nanocrystals for dual-mode cellular imaging. Chem Eur J 2011;17:6696-706. 
[116] Chen Y, Chen H, Zeng D, Tian Y, Chen F, Feng J, Shi J. Core/shell structured hollow mesoporous nanocapsules: a potential platform for simultaneous cell imaging and anticancer drug delivery. ACS Nano 2010;4:6001-13.

[117] An L, Hu H, Du J, Wei J, Wang L, Yang H, Wu D, Shi H, Li F, Yang S. Paramagnetic hollow silica nanospheres for in vivo targeted ultrasound and magnetic resonance imaging. Biomaterials 2014;35:5381-92.

[118] Liu T, Li L, Teng X, Huang X, Liu H, Chen D, Ren J, He J, Tang F. Single and repeated dose toxicity of mesoporous hollow silica nanoparticles in intravenously exposed mice. Biomaterials 2011;32:1657-68.

[119] He Q, Zhang Z, Gao F, Li Y, Shi J. In vivo biodistribution and urinary excretion of mesoporous silica nanoparticles: effects of particle size and PEGylation. Small 2011;7:27180.

[120] He Q, Zhang Z, Gao Y, Shi J, Li Y. Intracellular localization and cytotoxicity of spherical mesoporous silica nano- and microparticles. Small 2009;5:2722-9. 


\section{Tables}

\section{Table 1}

Overview of templates used for interfacial synthesis of silica nanocapsules.

\begin{tabular}{|c|c|c|c|}
\hline Template types & Solid nanoparticles & Emulsion droplets & Gas bubbles \\
\hline $\begin{array}{l}\text { Physicochemical } \\
\text { characteristics }\end{array}$ & $\begin{array}{l}\text { - 20-500 nm } \\
\text { - Highly monodisperse } \\
\text { - Stiff structure } \\
\text { - Some templates require } \\
\text { additional surface- } \\
\text { modification step(s) to form } \\
\text { silica having specific pore } \\
\text { structure }\end{array}$ & $\begin{array}{l}\text { - } ~ 30-500 \text { nm } \\
\text { - Monodisperse } \\
\text { - Flexible structure } \\
\text { - Surfactants used for droplet } \\
\text { stabilization can function as } \\
\text { reaction sites to form silica } \\
\text { and as pore-structure } \\
\text { directing agent }\end{array}$ & $\begin{array}{l}\text { - 100-800 nm } \\
\text { - Polydisperse } \\
\text { - Flexible structure } \\
\text { - Surfactants used for bubble } \\
\text { stabilization can function as } \\
\text { reaction sites to form silica } \\
\text { and as pore-structure } \\
\text { directing agent }\end{array}$ \\
\hline Reaction sites & - At solid-liquid interface & - At liquid-liquid interface & - At gas-liquid interface \\
\hline $\begin{array}{l}\text { Template } \\
\text { removal }\end{array}$ & $\begin{array}{l}\text { - Mandatory } \\
\text { - Use harsh conditions e.g., } \\
\text { strong acid/base or high } \\
\text { temperature }\end{array}$ & $\begin{array}{l}\text { - Optional } \\
\text { - Use mild conditions e.g., } \\
\text { ethanol }\end{array}$ & - Unnecessary \\
\hline $\begin{array}{l}\text { Cargo } \\
\text { encapsulation }\end{array}$ & $\begin{array}{l}\text { - Diffusion into porous } \\
\text { template (pre-loading) } \\
\text { • Diffusion through porous } \\
\text { shell into hollow core after } \\
\text { template removal (post- } \\
\text { loading) } \\
\text { - Incorporation of } \\
\text { hydrophobic cargo by } \\
\text { dispersing template (pre- } \\
\text { loading) or nanocapsule } \\
\text { (post-loading) in organic } \\
\text { solvent containing the cargo }\end{array}$ & $\begin{array}{l}\text { - Solubilization in either oil- } \\
\text { or water-phase prior to } \\
\text { formation of oil-in-water or } \\
\text { water-in-oil emulsion } \\
\text { template, respectively (pre- } \\
\text { loading) } \\
\text { - Diffusion through porous } \\
\text { shell into hollow core after } \\
\text { template removal (post- } \\
\text { loading) } \\
\text { - Incorporation of } \\
\text { hydrophobic cargo by }\end{array}$ & $\begin{array}{l}\text { - Diffusion through porous } \\
\text { shell into hollow core after } \\
\text { template removal (post- } \\
\text { loading) } \\
\text { - Incorporation of } \\
\text { hydrophobic cargo by } \\
\text { dispersing nanocapsule in } \\
\text { organic solvent containing } \\
\text { the cargo }\end{array}$ \\
\hline
\end{tabular}




\begin{tabular}{|c|c|c|c|}
\hline & & $\begin{array}{l}\text { utilizing oil-in-water } \\
\text { emulsion template }\end{array}$ & \\
\hline Challenges & $\begin{array}{l}\text { - Multistep routes toward } \\
\text { nanocapsules may lower the } \\
\text { yield and reduce batch-to- } \\
\text { batch reproducibility, hence } \\
\text { ineffective for scale-up } \\
\text { - Harsh conditions during } \\
\text { template removal may } \\
\text { influence structural integrity } \\
\text { of the shells } \\
\text { - Some surfactants used as } \\
\text { pore-structure directing } \\
\text { agents may be toxic }\end{array}$ & $\begin{array}{l}\text { • Emulsions are metastable } \\
\text { systems that can ultimately } \\
\text { separate into two phases } \\
\text { through coalescence or } \\
\text { Ostwald ripening at a certain } \\
\text { period of time } \\
\text { • High concentration of } \\
\text { surfactant is usually required } \\
\text { to stabilize emulsions } \\
\text { • Some surfactants and liquid } \\
\text { templates may be toxic }\end{array}$ & $\begin{array}{l}\text { - Controlling bubble size and } \\
\text { silica synthesis are difficult, } \\
\text { which can result in poly- } \\
\text { disperse nanocapsules with } \\
\text { deformed shell and non- } \\
\text { uniform thickness, hence } \\
\text { uneconomical for scale-up } \\
\text { - Cargo residues left on the } \\
\text { shell surface after post- } \\
\text { loading cause burst release } \\
\text { - Some surfactants may be } \\
\text { toxic }\end{array}$ \\
\hline
\end{tabular}




\section{Table 2}

Representative examples of sacrificial core materials used for synthesizing hollow-core silicashell nanocapsules.

\begin{tabular}{|c|c|c|c|c|c|c|}
\hline Core composition & Surface groups & $\begin{array}{c}\text { Silica } \\
\text { precursor }\end{array}$ & $\begin{array}{c}\text { Core } \\
\text { diameter } \\
\text { [nm] }\end{array}$ & $\begin{array}{c}\text { Shell } \\
\text { thickness } \\
\text { [nm] }\end{array}$ & $\begin{array}{c}\text { Core-removal } \\
\text { treatment }\end{array}$ & Ref. \\
\hline Silica & $\equiv \mathrm{Si}-\mathrm{OH}$ & $\begin{array}{c}\mathrm{C}_{18} \mathrm{TMS} \\
\text { and TEOS }\end{array}$ & 130 & 30 & $\mathrm{Na}_{2} \mathrm{CO}_{3}\left(80^{\circ} \mathrm{C}\right)$ & [14] \\
\hline $\begin{array}{l}\text { Hematite } \\
\left(\alpha-\mathrm{Fe}_{2} \mathrm{O}_{3}\right)\end{array}$ & $-\mathrm{OH}$ & $\begin{array}{c}\mathrm{C}_{18} \mathrm{TMS} \\
\text { and TEOS }\end{array}$ & 120 & 15 & $\mathrm{HCl}\left(80^{\circ} \mathrm{C}\right)$ & [23] \\
\hline Carbon & $\begin{array}{c}-\mathrm{OH} \text { and } \\
-\mathrm{C}=\mathrm{O}\end{array}$ & TEOS & 85 & 20 & $450^{\circ} \mathrm{C}$ & $\begin{array}{l}{[24,} \\
25]\end{array}$ \\
\hline $\begin{array}{l}\text { Poly(vinylbenzyl } \\
\text { chloride)*1 }^{* 1}\end{array}$ & $\begin{array}{c}-\mathrm{C}_{6} \mathrm{H}_{4}-\mathrm{CH}_{2} \mathrm{Cl} \rightarrow \\
-\mathrm{Si}\left(\mathrm{OCH}_{3}\right)_{3}\end{array}$ & TEOS & 86 & 19 & $600^{\circ} \mathrm{C}$ & [27] \\
\hline $\begin{array}{l}\text { Poly(tert- } \\
\text { butylacrylate) }\end{array}$ & $-\mathrm{NH}_{3}^{+}$ & TEOS & $30-180^{\dagger}$ & $20-95^{\ddagger}$ & Ethanol & [28] \\
\hline Poly(styrene) & $\begin{array}{c}-\mathrm{NH}_{2} ; \\
-\mathrm{NH}_{3}^{+} /-\mathrm{COO}^{-}\end{array}$ & $\mathrm{Na}_{2} \mathrm{SiO}_{3}$ & $19-182^{\dagger}$ & $3-10^{\ddagger}$ & $450^{\circ} \mathrm{C}$ & [29] \\
\hline $\begin{array}{l}\text { Calcium } \\
\text { carbonate*2 }^{* 2}\end{array}$ & $\begin{array}{c}-\mathrm{CO}_{3}^{2-} \rightarrow \\
-\mathrm{NH}_{3}{ }^{+}\end{array}$ & $\mathrm{Na}_{2} \mathrm{SiO}_{3}$ & $40-50$ & 20 & $\mathrm{HCl}$ & [34] \\
\hline Hydroxyapatite*2 & $\begin{array}{c}-\mathrm{PO}_{4}^{2-} \rightarrow \\
-\mathrm{NH}_{3}{ }^{+}\end{array}$ & TEOS & 68 & 6.5 & $\mathrm{HCl}$ & [39] \\
\hline
\end{tabular}

*The pristine nanoparticle surfaces were modified either covalently ${ }^{1}$ or electrostatically ${ }^{2}$ prior to silica growth. Tunable core size ${ }^{\dagger}$ and shell thickness ${ }^{\ddagger}$. Abbreviation: $\mathrm{C}_{18} \mathrm{TMS}$, octadecyltrimethoxysilane; TEOS, tetraethoxysilane. 


\section{Table 3}

Representative examples of oil-in-water $(\mathrm{O} / \mathrm{W})$ and water-in-oil (W/O) emulsion droplet as a template for the synthesis of silica nanocapsules.

\begin{tabular}{|c|c|c|c|c|c|c|c|}
\hline $\begin{array}{c}\text { Dispersed } \\
\text { phase }\end{array}$ & $\begin{array}{c}\text { Continuous } \\
\text { phase }\end{array}$ & Surfactant & $\begin{array}{c}\text { Silica } \\
\text { precursor }\end{array}$ & Cargo & $\begin{array}{c}\text { Nanocapsule } \\
\text { diameter } \\
{[\mathrm{nm}]}\end{array}$ & $\begin{array}{c}\text { Shell } \\
\text { thickness } \\
\text { [nm] }\end{array}$ & Ref. \\
\hline \multicolumn{8}{|l|}{$\underline{\mathrm{O} / \mathrm{W} \text { emulsions }}$} \\
\hline Ethyl ether & Water & CTAB & TEOS & $\begin{array}{l}\text { Fluorescent } \\
\text { (pyrene) }\end{array}$ & 120 & 20 & [49] \\
\hline $\begin{array}{l}\text { TEOS and } \\
N, N \text {-dimethyl- } \\
\text { formamide }\end{array}$ & Water & CTAC & TEOS & $\begin{array}{l}\text { Gold } \\
\text { nanoparticles; } \\
\text { or magnetic } \\
\text { nanoparticles } \\
\left(\mathrm{Fe}_{3} \mathrm{O}_{4}\right)\end{array}$ & 200 & 60 & [50] \\
\hline TEOS & $\begin{array}{l}\text { Ethanol } \\
\text { and water }\end{array}$ & CTAB & TEOS & $\mathrm{n} / \mathrm{a}$ & $150-720^{\dagger}$ & $40-140^{\ddagger}$ & [51] \\
\hline $\begin{array}{l}\text { TEOS and n- } \\
\text { heptane }\end{array}$ & Water & CTAB & TEOS & $\begin{array}{l}\text { Gold } \\
\text { nanoparticles }\end{array}$ & 280 & 1 & [52] \\
\hline Hexadecane & Water & Brij $^{\circledR 97}$ & $\begin{array}{l}\text { OTMS and } \\
\text { TMOS }\end{array}$ & $\mathrm{n} / \mathrm{a}$ & 98 & 33 & [53] \\
\hline Ethyl butyrate & Water & $\begin{array}{l}\text { Tween }^{\circledR} 80 \text { and } \\
\text { lecithin }\end{array}$ & $\begin{array}{l}\text { OTMS and } \\
\text { TMOS }\end{array}$ & $\mathrm{n} / \mathrm{a}$ & 77 & 21 & [54] \\
\hline Benzene & $\begin{array}{l}\text { Ionic liquid } \\
\left(\mathrm{BmimBF}_{4}\right)\end{array}$ & Triton $^{\mathrm{TM}} \mathrm{X}-100$ & TEOS & $\mathrm{n} / \mathrm{a}$ & 95 & $\mathrm{n} / \mathrm{a}$ & [55] \\
\hline $\begin{array}{l}\text { Perfluoro- } \\
\text { decalin }\end{array}$ & Water & Pluronic ${ }^{\circledR} \mathrm{F} 68$ & $\begin{array}{l}\text { Prehydro- } \\
\text { lyzed } \\
\text { TMOS }\end{array}$ & $\begin{array}{l}\text { Perfluorode- } \\
\text { calin }\end{array}$ & $230-250^{\dagger}$ & $\mathrm{n} / \mathrm{a}$ & [56] \\
\hline $\begin{array}{l}\text { Labrafac }^{\circledR} \text { WL } \\
1349\end{array}$ & Water & Kolliphor $^{\mathrm{TM}}$ ELP & APTES & $\mathrm{n} / \mathrm{a}$ & 120 & $\mathrm{n} / \mathrm{a}$ & [57] \\
\hline
\end{tabular}




\begin{tabular}{|c|c|c|c|c|c|c|c|}
\hline Miglyol $^{\circledR} 812$ & Water & SurSi peptide & TEOS & $\begin{array}{l}\text { Fipronil } \\
\text { insecticide }\end{array}$ & $140-288^{\dagger}$ & $8-44^{\ddagger}$ & $\begin{array}{l}60- \\
62]\end{array}$ \\
\hline Miglyol $^{\circledR} 812$ & Water & D4S2 protein & TEOS & $\mathrm{n} / \mathrm{a}$ & 249 & 26 & [63] \\
\hline Soybean oil & Water & $\begin{array}{l}\text { Lecithin and } \\
\text { poly(lysine) }\end{array}$ & TEOS & $\begin{array}{l}\text { Nile red and } \\
\text { CdSe quantum } \\
\text { dots }\end{array}$ & $\sim 200^{\dagger}$ & $5-20^{\ddagger}$ & [64] \\
\hline \multicolumn{8}{|c|}{$\underline{\text { W/O emulsions }}$} \\
\hline Water & $\begin{array}{l}\text { Cyclohexa } \\
\text { ne }\end{array}$ & $\begin{array}{l}\text { Triton }^{\mathrm{TM}} \mathrm{X}-100 \\
\text { and n-hexanol } \\
\text { (co-surfactant) }\end{array}$ & TEOS & $\begin{array}{l}\text { Magnetic } \\
\text { nanoparticle } \\
\left(\mathrm{Fe}_{3} \mathrm{O}_{4}\right)\end{array}$ & 30 & 5 & [65] \\
\hline Water & $\begin{array}{l}\text { Cyclohexa } \\
\text { ne }\end{array}$ & $\begin{array}{l}\text { Triton }^{\mathrm{TM}} \mathrm{X}-100 \\
\text { and n-octanol } \\
\text { (co-surfactant) }\end{array}$ & TEOS & $\begin{array}{l}\text { Magnetic } \\
\text { nanoparticle } \\
\left(\mathrm{Fe}_{3} \mathrm{O}_{4}\right)\end{array}$ & 40 & 11 & [66] \\
\hline Water & $\begin{array}{l}\text { Cyclohexa } \\
\text { ne }\end{array}$ & $\begin{array}{l}\text { P(E/B)-PEO or } \\
\text { Span }^{\circledR} 80\end{array}$ & TEOS & $\mathrm{n} / \mathrm{a}$ & 600 & 44 & [67] \\
\hline Water & Decane & $\begin{array}{l}\text { IGEPAL }{ }^{\circledR} \text { CA- } \\
520 \text { and n- } \\
\text { hexanol (co- } \\
\text { surfactant) }\end{array}$ & $\begin{array}{l}\text { TEOS and } \\
\text { APTMS }\end{array}$ & $\begin{array}{l}\text { Enzyme } \\
\text { (horseradish } \\
\text { peroxidase, } \\
\text { superoxide } \\
\text { dismutase and } \\
\text { catalase) }\end{array}$ & 50 & 10 & $\begin{array}{l}68, \\
69]\end{array}$ \\
\hline Water & $\begin{array}{l}\text { Cyclohexa } \\
\text { ne }\end{array}$ & $\begin{array}{l}\text { Triton }^{\mathrm{TM} X} \text {-100 } \\
\text { and n-hexanol } \\
\text { (co-surfactant) }\end{array}$ & TEOS & $\begin{array}{l}\text { Ruthenium- } \\
\text { based } \\
\text { fluorescent } \\
\text { dye }\end{array}$ & 100 & $\mathrm{n} / \mathrm{a}$ & [70] \\
\hline
\end{tabular}

Tunable nanocapsule diameter ${ }^{\dagger}$ and shell thickness ${ }^{\ddagger}$. All diameter and shell thickness were determined by transmission electron microscopy (TEM). CTAB: cetyltrimethylammonium bromide. CTAC: cetyltrimethylammonium chloride. MPTMS: 3-mercaptopropyltrimethoxysilane; $\quad$ OTMS: octadecyltrimethoxysilane; P(E/B)-PEO: poly(ethylene-co-butylene)-b-poly(ethylene oxide) ; TEOS: tetraethoxysilane. TMOS: tetramethoxysilane. n/a: not available. 


\section{Table 4}

Representative examples of silica nanocapsules for encapsulation and controlled release.

\begin{tabular}{|c|c|c|c|c|c|c|}
\hline Template & $\begin{array}{c}\text { Pore size } \\
\text { [nm] }\end{array}$ & Cargo & $\begin{array}{c}\text { Encapsulation } \\
\text { approach }\end{array}$ & $\begin{array}{c}\text { Surface } \\
\text { modification }\end{array}$ & $\begin{array}{c}\text { Release } \\
\text { mechanism }\end{array}$ & Ref. \\
\hline $\begin{array}{l}\text { Silica } \\
\text { nanoparticle }\end{array}$ & 3.6 & Doxorubicin & Post-loading & Unmodified & Passive diffusion & [14] \\
\hline $\begin{array}{l}\text { Silica } \\
\text { nanoparticle }\end{array}$ & $3.2-14.6^{\dagger}$ & siRNA & Post-loading & PEI & Passive diffusion & [17] \\
\hline $\begin{array}{l}\text { Silica } \\
\text { nanoparticle }\end{array}$ & 3.8 & Doxorubicin & Post-loading & $\begin{array}{l}\text { [2]rotaxanes } \\
(\mathrm{TEG}, \mathrm{FA} \text {, and } \\
\alpha-\mathrm{CD})\end{array}$ & $\begin{array}{l}\text { Diffusion triggered } \\
\text { by redox reactions } \\
\text { of } \alpha-C D\end{array}$ & [20] \\
\hline $\begin{array}{l}\text { Silica } \\
\text { nanoparticle }\end{array}$ & $3.2-12.6^{\dagger}$ & Doxorubicin & Post-loading & Unmodified & $\begin{array}{l}\text { Passive diffusion } \\
\text { (release kinetic is } \\
\text { affected by } \mathrm{pH} \text { ) }\end{array}$ & [22] \\
\hline $\begin{array}{l}\text { Hematite } \\
\text { nanoparticle }\end{array}$ & 3.54 & Ibuprofen & Post-loading & Unmodified & Passive diffusion & [23] \\
\hline $\begin{array}{l}\text { PBA } \\
\text { nanoparticle }\end{array}$ & 2.6 & Doxorubicin & Post-loading & Unmodified & $\begin{array}{l}\text { Passive diffusion } \\
\text { (release kinetic is } \\
\text { affected by } \mathrm{pH} \text { ) }\end{array}$ & [28] \\
\hline PS nanoparticle & $\mathrm{n} / \mathrm{a}$ & Bortezomib & Post-loading & Unmodified & Passive diffusion & [31] \\
\hline PS nanoparticle & 27.1 & TNF- $\alpha$ & Post-loading & $\begin{array}{l}\text { Chitosan, target- } \\
\text { ing antibody }\end{array}$ & $\begin{array}{l}\text { Diffusion triggered } \\
\text { by } \mathrm{pH} \text { changes }\end{array}$ & [32] \\
\hline PS nanoparticle & $\mathrm{n} / \mathrm{a}$ & $\begin{array}{l}\text { Drug } \\
\text { (camptothecin/ } \\
\text { doxorubicin) } \\
\text { and magnetic } \\
\text { nanoparticles }\end{array}$ & $\begin{array}{l}\text { Post-loading } \\
\text { (drug), and } \\
\text { pre-loading } \\
\text { (magnetic } \\
\text { nanoparticles) }\end{array}$ & Unmodified & $\begin{array}{l}\text { Diffusion of the } \\
\text { drug triggered by } \\
\text { radio frequency } \\
\text { magnetic fields }\end{array}$ & [33] \\
\hline
\end{tabular}




\begin{tabular}{|c|c|c|c|c|c|c|}
\hline PS nanoparticle & $\mathrm{n} / \mathrm{a}$ & Ibuprofen & Post-loading & $\begin{array}{l}\beta \text {-CD and Azo- } \\
\text { containing block } \\
\text { copolymer }\end{array}$ & $\begin{array}{l}\text { Diffusion triggered } \\
\text { by light }\end{array}$ & [113] \\
\hline $\begin{array}{l}\mathrm{CaCO}_{3} \\
\text { nanoparticle }\end{array}$ & 1.0 & Cefradine & Post-loading & Unmodified & Passive diffusion & [34] \\
\hline $\begin{array}{l}\mathrm{CaCO}_{3} \\
\text { nanoparticle }\end{array}$ & $4.0-5.0$ & Avermectin & Post-loading & Unmodified & Passive diffusion & [35] \\
\hline $\begin{array}{l}\text { Ethyl acetate } \\
\text { O/W emulsion }\end{array}$ & $3.0-5.0$ & Tebuconazole & Pre-loading & Unmodified & Passive diffusion & [59] \\
\hline $\begin{array}{l}\text { Miglyol }^{\circledR} 812 \\
\text { O/W emulsion }\end{array}$ & $\mathrm{n} / \mathrm{a}$ & Fipronil & Pre-loading & Unmodified & Passive diffusion & $\begin{array}{l}{[60,} \\
61]\end{array}$ \\
\hline $\begin{array}{l}\text { Soybean O/W } \\
\text { emulsion }\end{array}$ & $\mathrm{n} / \mathrm{a}$ & $\begin{array}{l}\text { Nile red and } \\
\text { CdSe quantum } \\
\text { dots }\end{array}$ & Pre-loading & $\begin{array}{l}\text { Hyaluronic acid } \\
\text { or poly-L-lysine }\end{array}$ & Passive diffusion & [64] \\
\hline $\begin{array}{l}\text { TEOS O/W } \\
\text { emulsion }\end{array}$ & 2.9 & Ibuprofen & Post-loading & $\begin{array}{l}\text { Layer-by-layer } \\
\text { films of cationic } \\
\text { / anionic } \\
\text { polymers }\end{array}$ & $\begin{array}{l}\text { Passive diffusion } \\
\text { (release kinetics is } \\
\text { affected by pH or } \\
\text { salt concentrations) }\end{array}$ & [109] \\
\hline $\begin{array}{l}\text { Sonication- } \\
\text { induced air } \\
\text { bubble }\end{array}$ & 3.1 & Flurbiprofen & Post-loading & $\begin{array}{l}\text { Amine } \\
\text { functional group }\end{array}$ & Passive diffusion & {$[77]$} \\
\hline
\end{tabular}

†Tunable pore sizes. Abbreviation: CD, cyclodextrin; FA, folic acid; PBA, poly(tert-butylacrylate); PEI, poly(ethyleneimine); PS, poly(styrene); Redox, reduction-oxidation; O/W, oil-in-water; TEG, tetraethylene glycol; TEOS, tetraethoxysilane; TNF- $\alpha$, tumor necrosis factor $\alpha$; $/ \mathrm{a}$, not available. 


\section{Figure Captions}

Fig. 1. Schematic of a cargo-loaded, multifunctional, stimuli-sensitive silica nanocapsule as a nanocarrier platform.

Fig. 2. Schematic procedure for the synthesis of a cargo-loaded, surface-functionalized silica nanocapsule. (i) Preparation of a template i.e., solid nanoparticle, emulsion droplet, or gas bubble which is modified by either molecules or biomolecules adsorbed on the template's surface; (ii) addition of a silica precursor; (iii) formation of silica shell; (iv) removal of the template; (v) loading of cargo molecules; and (vi) surface functionalization.

Fig. 3. Transmission electron microscopy (TEM) images of silica nanocapsules prepared by templating solid nanoparticles. (A, B) Core-shell nanoparticles composed of a dense silica nanoparticle $\left(\mathrm{dSiO}_{2}\right)$ core (dark) and a mesoporous silica nanoparticle shell (light) (A) and hollow silica nanocapsules after template-removal (B). (C) Hollow silica nanocapsules after removal of poly(styrene) latex nanoparticle templates.

(A, B) Adapted with permission from Ref. [16]. Copyright (2014) Nature Publishing Group.

(C) Reprinted from Ref. [30], Copyright (2010), with permission from Elsevier.

Fig. 4. Schematic diagram of hard-template removal via structural difference-based selective etching (Route $\mathrm{A}$ : in $\mathrm{Na}_{2} \mathrm{CO}_{3}$ solution. Route $\mathrm{B}$ : in ammonia solution).

Reprinted with permission from Ref. [14]. Copyright (2010) American Chemical Society.

Fig. 5. Transmission electron microscopy (TEM) images of silica nanocapsules obtained by templating oil-in-water (O/W) emulsion droplets. (A, B) Hollow mesoporous silica nanospheres. (C, D) Oil-core silica-shell nanocapsules (scale bar: $200 \mathrm{~nm}$ ). 
(A) Reprinted with permission from Ref. [50]. Copyright (2010) American Chemical Society.

(B) Reprinted from Ref. [51], Copyright (2010), with permission from Elsevier. (C) Reproduced from Ref. [60] with permission from The Royal Society of Chemistry. (D) Reprinted with permission from Ref. [63]. Copyright (2015) American Chemical Society.

Fig. 6. Transmission electron microscopy (TEM) images of silica nanocapsules obtained by templating water-in-oil (W/O) emulsion droplets. (A) Hollow silica nanospheres. (B) Fluorescent-doped hollow silica nanospheres. (C) Hollow silica nanocapsules. (D) Enzyme (horseradish peroxidase) encapsulated silica nanocapsules (scale bar: $50 \mathrm{~nm}$ ).

(A) Reproduced from Ref. [65] with permission from The Royal Society of Chemistry. (B) Reproduced from Ref. [66] with permission from The Royal Society of Chemistry. (C) Reprinted with permission from Ref. [67]. Copyright (2012) American Chemical Society. (D) Reprinted with permission from Ref. [68]. Copyright (2014) American Chemical Society.

Fig. 7. Silica nanocapsule prepared by templating gas bubbles. Top: Upon ultrasonic irradiation, the surfactant (i.e., $N$-lauroylsarcosine sodium) stabilizes the cavitating bubbles and induces nucleation and growth of silica encapsulating the bubbles. The surfactant/silica hybrid aggregates deposit as a disordered liquid-like phase and then evolve to ordered mesostructured in a time-dependent manner. Bottom: (A, B) Transmission electron microscopy (TEM) images of the hollow mesoporous silica nanoparticles after removal of the surfactant.

Adapted with permission from Ref. [77]. Copyright (2009) American Chemical Society.

Fig. 8. (A) Conceptual design of a bifunctional modular biomolecule, SurSi peptide, able to stabilize O/W nanoemulsions and to catalyze interfacial biomineralizing reactions through its surface-active module (in yellow and blue) and biosilicification-active module (in red), 
respectively, for the synthesis of oil-core silica-shell nanocapsules. (B) Schematic synthesis protocol and possible charge inversion of oil-core silica-shell nanocapsules by templating O/W nanoemulsions: nanoemulsions are stabilized using lecithin which can adsorb poly(lysine) to the nanoemulsions' surface to induce silica shell formation.

(A) Reproduced from Ref. [60] with permission from The Royal Society of Chemistry. (B) Reproduced with permission from Ref. [64]. Copyright (2015) John Wiley \& Sons Inc.

Fig. 9. Post-loading approach for the encapsulation of active molecules in pre-formed silica nanocapsules: (i) diffusion of active molecules; and (ii) encapsulation of the active molecules.

Fig. 10. Pre-loading approaches for the encapsulation of active molecules prior to the formation of silica nanocapsules. (A) Incorporation of active molecules in a pre-formed porous nanoparticle (e.g., calcium carbonate and carbon nanoparticles): (i) adsorption of active molecules; (ii) formation of silica shell; and (iii) removal of the core and encapsulation of active molecules. (B) Incorporation of active molecules during synthesis of the template (e.g., emulsion): (i) solubilization or dispersion of the active molecules in the template precursor; (ii) formation of silica shell; and (iii) removal of the core (optional) and encapsulation of active molecules.

Fig. 11. Silica nanocapsules as controlled-release nanocarriers in vitro. (A) pH-responsive nanocapsules: release of propidium iodide from hollow supramolecular nanovalve (SNV) systems with linkers (a) $N$-phenylaminomethyltriethoxysilane, (b) $N$ phenylaminopropyltrimethoxysilane, and (c) 3-iodopropyltrimethoxysilane. (B) Lightresponsive nanocapsules: release of ibuprofen under different light irradiation (a) at $37^{\circ} \mathrm{C}$ and (b) under the conversion of ultraviolet (UV) and visible (Vis) light. (C) Redox-responsive 
nanocapsules: release of doxorubicin (a) over $120 \mathrm{~min}$ and (b) over $26 \mathrm{~h}$ by addition of glutathione (GSH). (D) Radio frequency magnetic field-responsive nanocapsules: release of (a) hydrophobic camptothecin or (b) hydrophilic doxorubicin by applying radio frequency magnetic field on-off cycling (switch-on period $=10 \mathrm{~s}$, switch off $=5 \mathrm{~min}$ ) which can heat the magnetic nanoparticles thus generate temperature gradient between inside and outside of the spheres.

(A) Adapted with permission from Ref. [108]. Copyright (2009) American Chemical Society. (B) Adapted from Ref. [113] with permission from The Royal Society of Chemistry. (C) Adapted with permission from Ref. [20]. Copyright (2013) American Chemical Society. (D) Adapted with permission from Ref. [33]. Copyright (2010) American Chemical Society.

Fig. 12. In vivo enhanced drug delivery using hollow mesoporous silica nanoparticle (HMSN) having multiple functionalities (HMSN(DOX)-(w/o)TRC105) as a nanocarrier platform. HMSN(DOX)-(w/o)TRC105 comprises of a core (i.e., doxorubicin, DOX) and a silica shell functionalized with poly(ethylene glycol) (PEG), positron emission tomography (PET) imaging agent (i.e., ${ }^{64} \mathrm{Cu}$ ) and targeting molecule (i.e., thiolated anti-CD105 antibody, TRC105). w/o denotes with and without. (A) UV-Vis spectra of HMSN and HMSN(DOX) in aqueous solution. (B) $\mathrm{pH}$-sensitive release profiles of HMSN(DOX) at $\mathrm{pH} 5.0$ and $\mathrm{pH} 7.4$ in phosphate buffer saline (PBS) solution. (C) A schematic illustration showing the in vivo drug delivery after intravenous (i.v.) injection of HMSN(DOX)-(w/o)-TRC105 in 4T1 tumorbearing mouse. (D) Ex vivo near-IR fluorescence imaging of major organs after i.v. injection of HMSN(DOX)-(w/o)-TRC105 in 4T1 tumor-bearing mice. HMSN dose was $10 \mathrm{mg} / \mathrm{kg}$, while the DOX dose was $6.5 \mathrm{mg} / \mathrm{kg}$ (Excitation $465 \mathrm{~nm}$, Emission $580 \mathrm{~nm}$ ).

Reproduced with permission from Ref. [16]. Copyright (2014) Nature Publishing Group. 


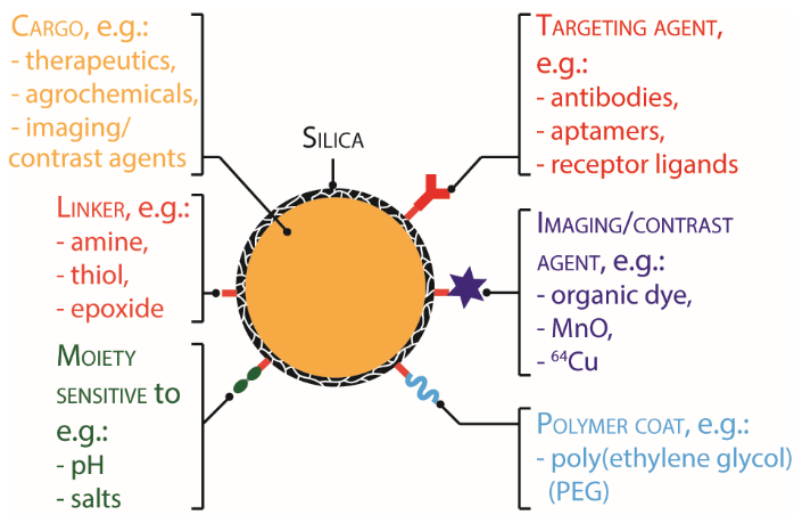

Fig. 1 


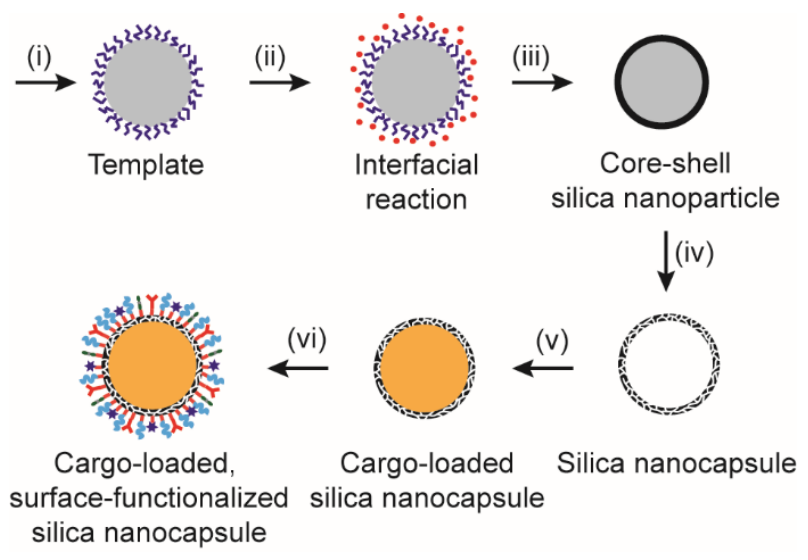

Fig. 2 

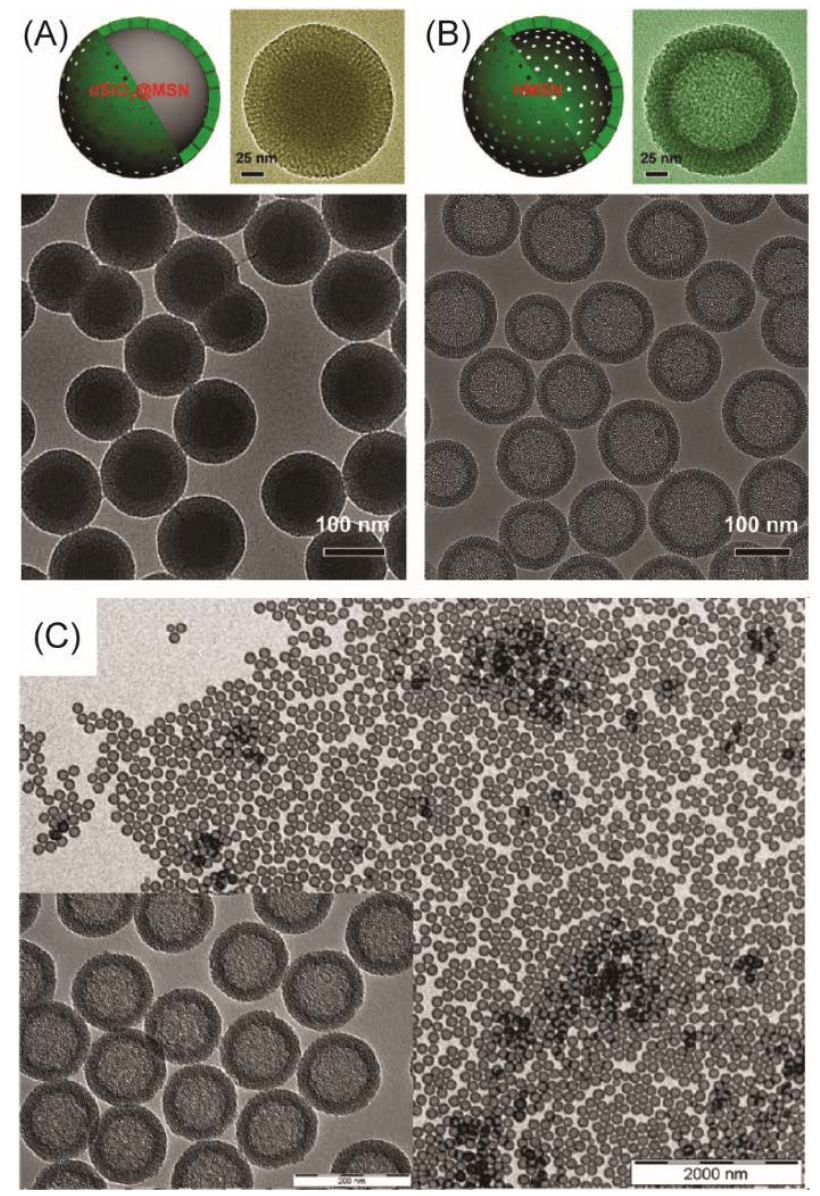

Fig. 3 


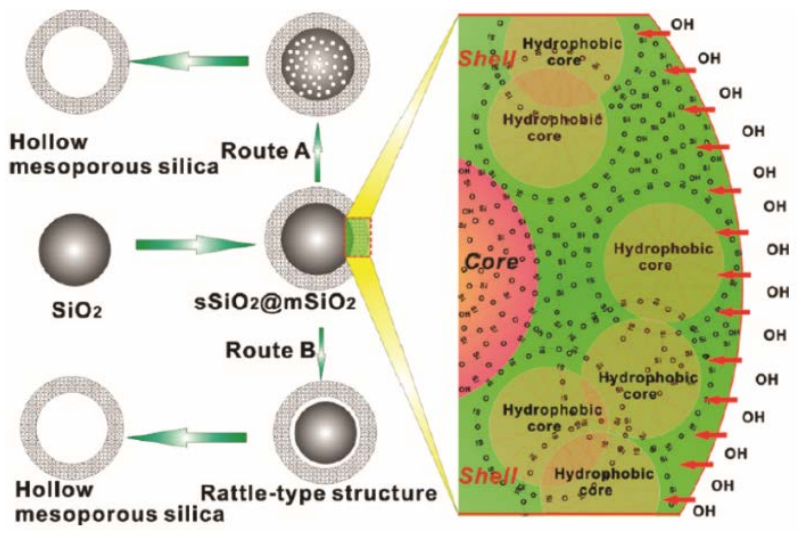

Fig. 4 


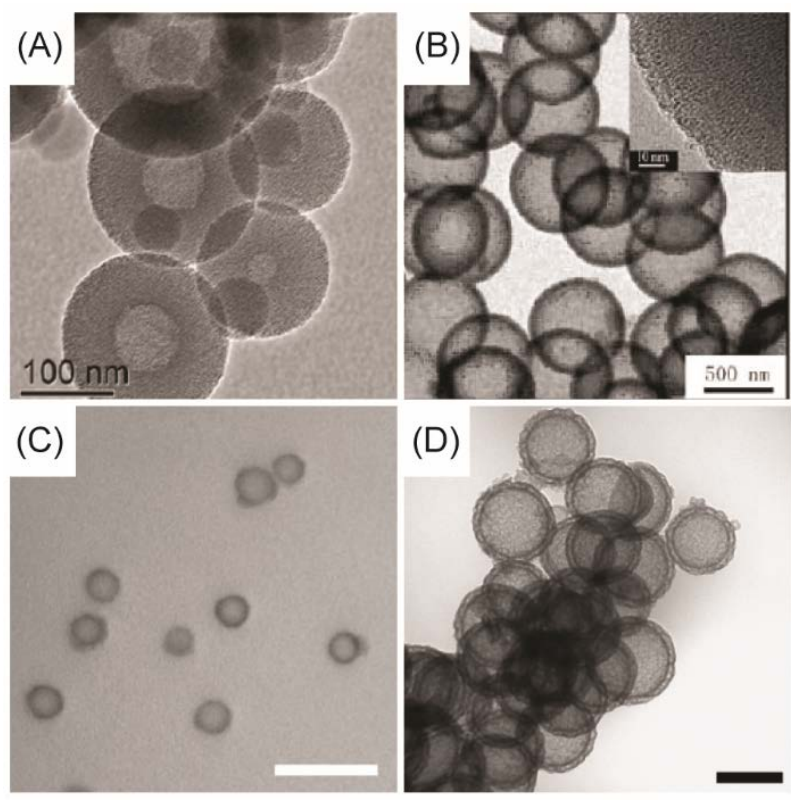

Fig. 5 


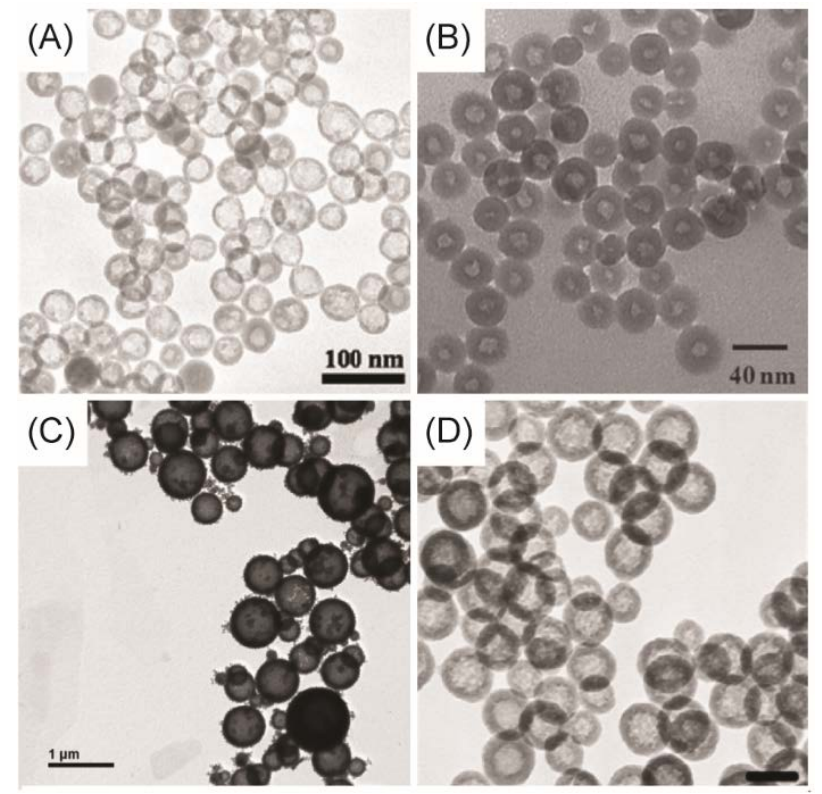

Fig. 6 

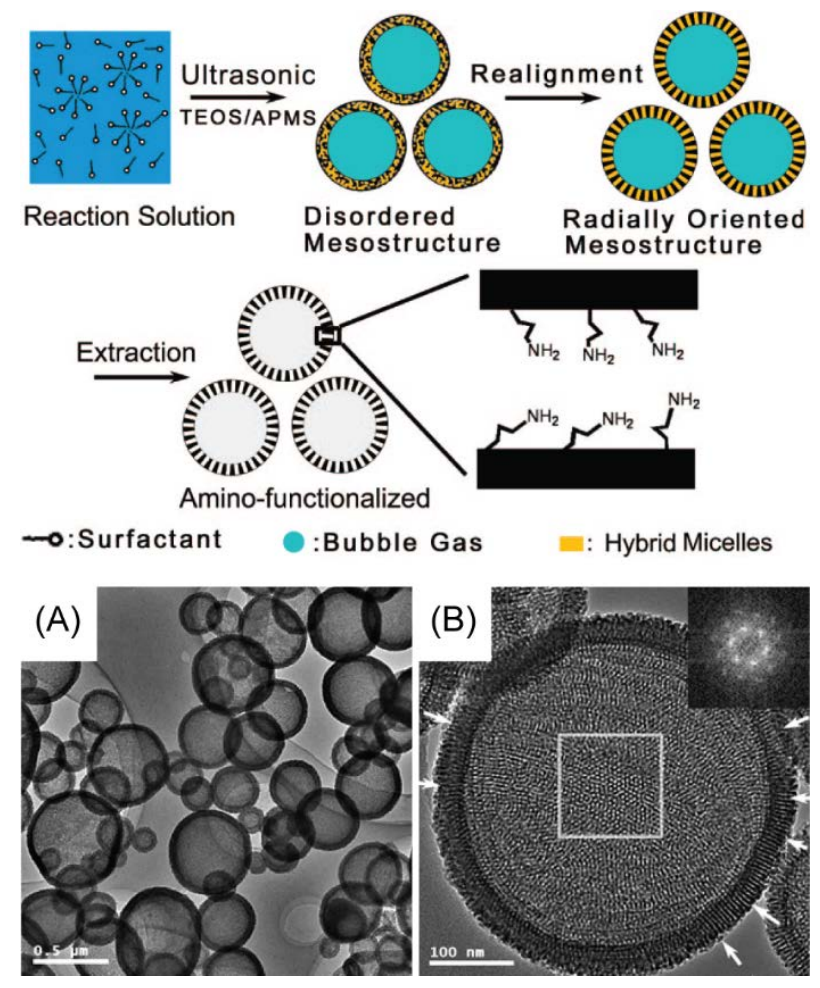

Fig. 7 


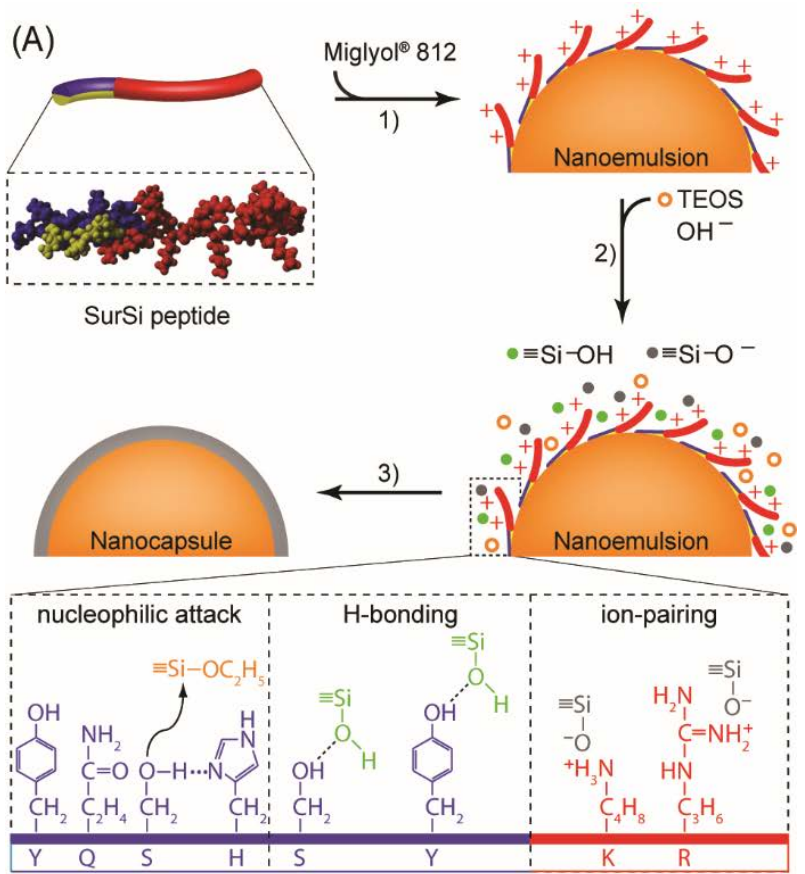

(B)

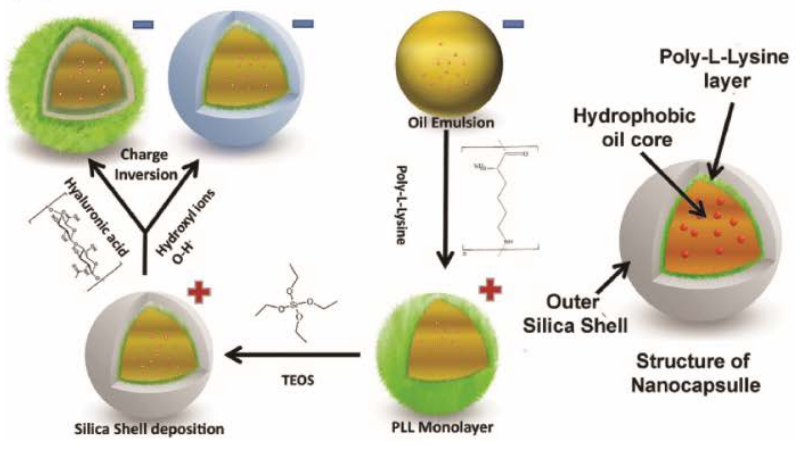

Fig. 8 


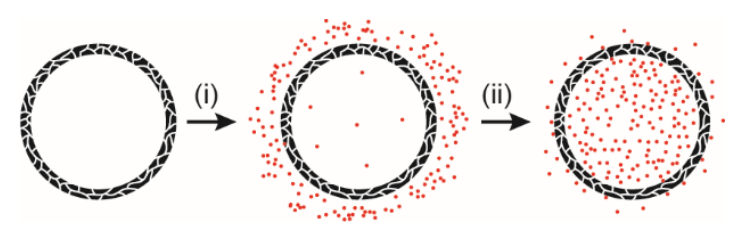

Fig. 9 


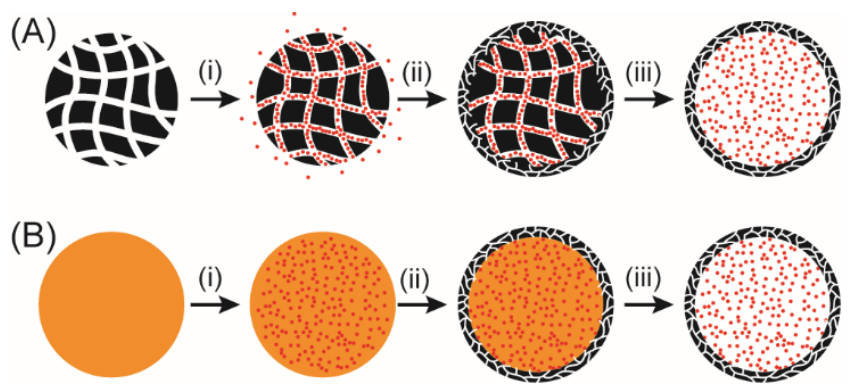

Fig. 10 
(A) $\mathrm{pH}$-responsive
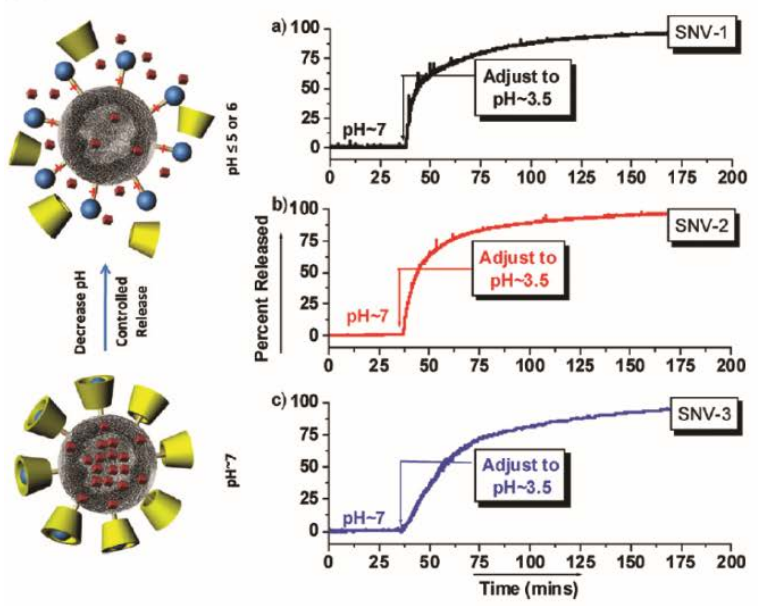

(C)Redox-responsive
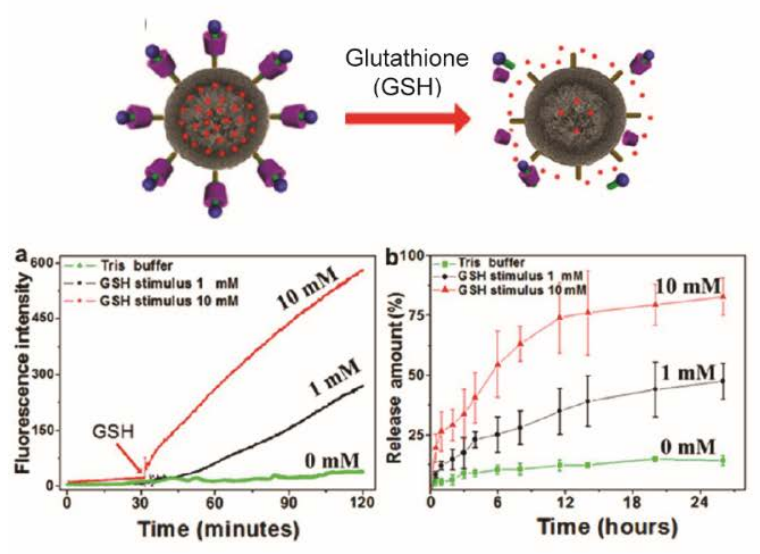

(B) Light-responsive
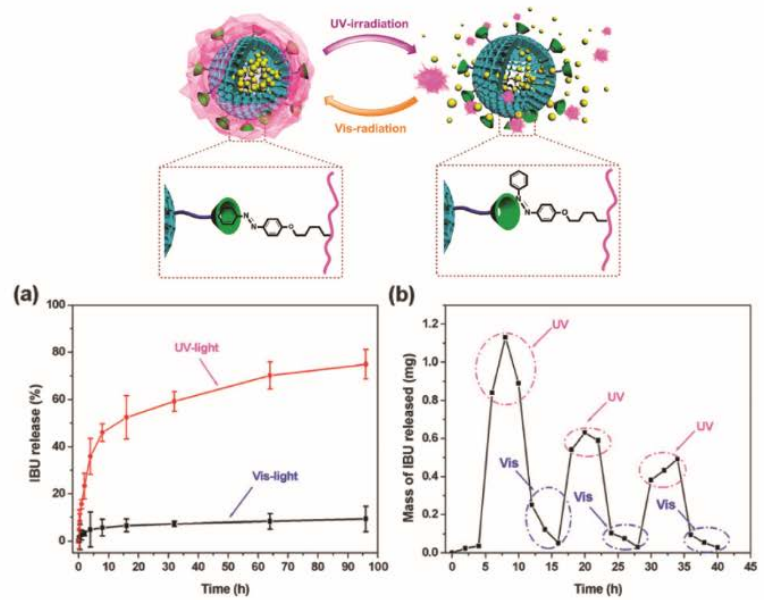

(D) Radio frequency magnetic field-responsive
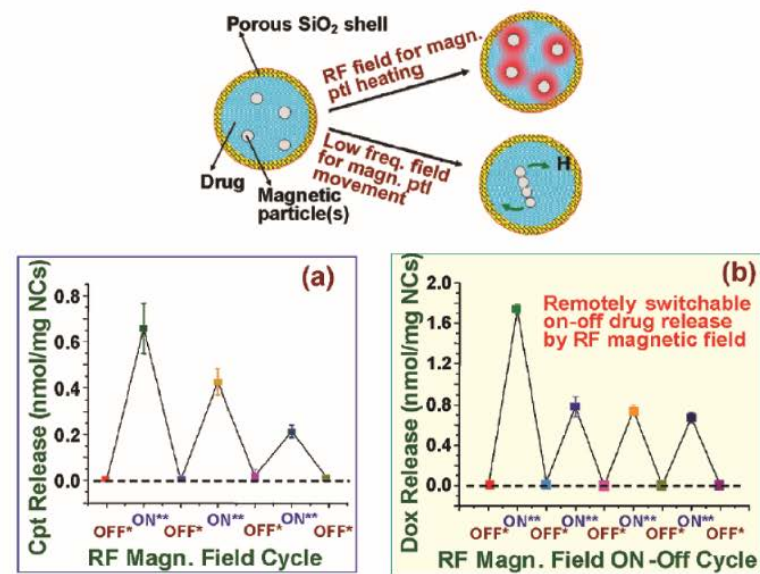

Fig. 11 

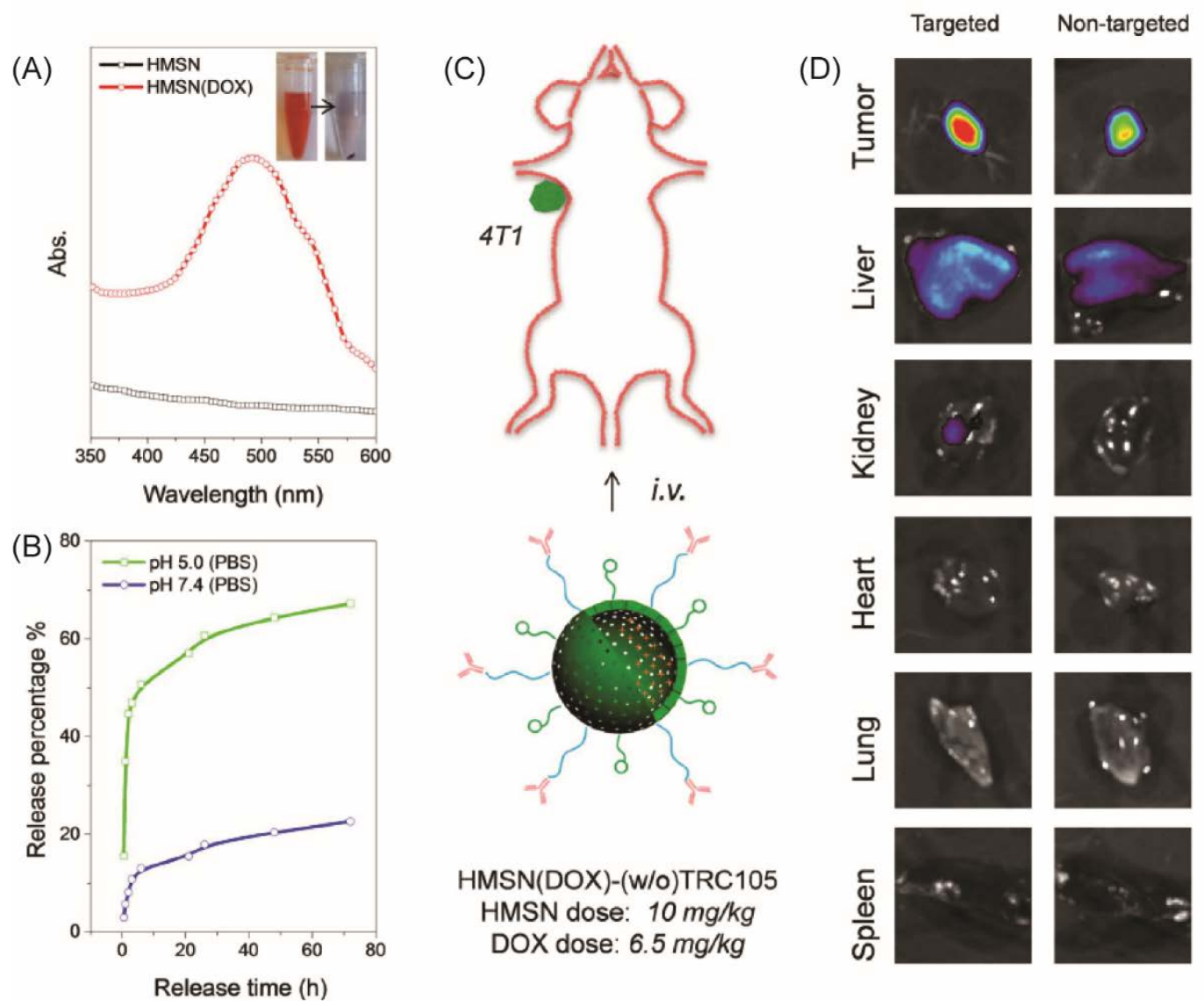

HMSN(DOX)-(w/o)TRC105 HMSN dose: $10 \mathrm{mg} / \mathrm{kg}$ DOX dose: $6.5 \mathrm{mg} / \mathrm{kg}$

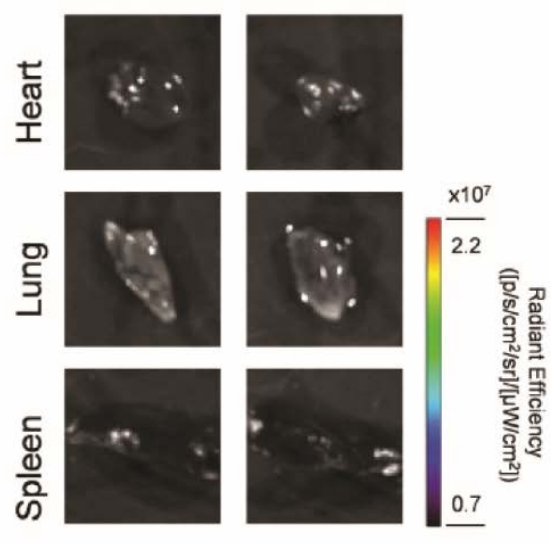

Fig. 12 


\section{Graphical Abstract}

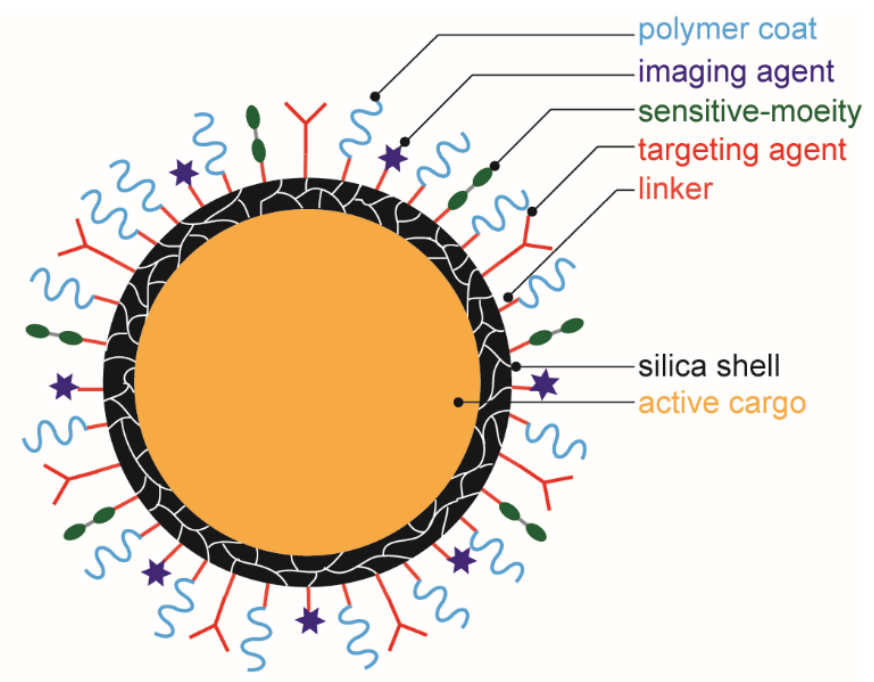

Silica Nanocapsule as A Multifunctional

Nanocarrier PlatForm 